Nat. Hazards Earth Syst. Sci., 20, 197-220, 2020

https://doi.org/10.5194/nhess-20-197-2020

(C) Author(s) 2020. This work is distributed under

the Creative Commons Attribution 4.0 License.

\title{
Sandbag replacement systems - a nonsensical and costly alternative to sandbagging?
}

\author{
Lena Lankenau, Christopher Massolle, Bärbel Koppe, and Veronique Krull \\ Institute for Hydraulic and Coastal Engineering, City University of Applied Sciences, \\ 28199 Bremen, Germany
}

Correspondence: Lena Lankenau (lena.lankenau@hs-bremen.de)

Received: 20 May 2019 - Discussion started: 27 May 2019

Revised: 21 November 2019 - Accepted: 27 November 2019 - Published: 17 January 2020

\begin{abstract}
In addition to flood defence with sandbags, different sandbag replacement systems (SBRSs) have been available for a number of years. The use of sandbags is timeconsuming as well as highly intensive in terms of materials and personnel. In contrast, SBRSs are reusable and require lower costs in terms of helpers and logistics, offsetting the comparatively higher initial investment costs through repeated use. So far, SBRSs have rarely been used in Germany in operational flood protection. The reasons lie in different financing modalities of investment, operational costs and low confidence in the technical performance of SBRSs. These problems are addressed by a research programme at the Institute of Hydraulic Engineering (IWA), City University of Applied Sciences, Bremen. A series of systematic large-scale tests of sandbag systems and SBRSs with a focus on functionality, stability and handling was carried out. The results showed that the majority of the SBRSs tested are able to provide protection comparable to that of sandbag systems but with a significantly reduced use of materials, simplified logistics and fewer helpers. Nevertheless, it is advisable to develop and perform well-defined certification tests for SBRSs, in order to define clear instructions for and to identify limits to the use of certain SBRSs. For example, not all systems work equally well on different surfaces.

Supplementary to the practical tests, costs of the procurement and use of various sandbag systems and SBRSs were determined on the basis of realistic scenarios. This provides a methodology as well as concrete figures to cost the provision and use of different protection systems from a holistic perspective. It turns out that the higher investment costs of the SBRSs investigated compared to sandbag systems are already offset on the second use of the reusable systems.
\end{abstract}

\section{Introduction}

The classic aid in operative flood defence is the sandbag. Socalled sandbag replacement systems (SBRSs) have also been available for some time now although their use is still very limited. Figure 1 shows such mobile, location-independent flood defence systems, which can be subdivided into tube, basin, flap, trestle, dam or panel systems, and bulk elements. The systems counteract flooding either by their bulk weight, which is induced by water, sand or concrete (in container and bulk systems), or by their geometry in connection with the vertical hydrostatic water pressure (in flap, trestle, dam and air-filled tube systems - not shown in Fig. 1), with both approaches resulting in frictional forces on the ground. Panel systems consist of panels which are held in place by sticks driven in the ground on alternate sides. But, commonly, location-independent mobile flood protection systems do not need additional anchoring to the ground. However, some producers offer such a possibility, which introduces a safety surplus or can be necessary when high-flow velocities or wind stress on the non-jet-impounded system are expected. Sandbags as well as SBRSs are used in flood disaster management, especially in cases when permanent flood protection systems like dikes fail or when no permanent flood protection schemes are available because the endangered area was thought not to be at risk. Thus, sandbags as well as SBRSs are used in extreme flood events. There has been no regulatory obligation to demonstrate the functionality of an SBRS so far. In general, however, SBRSs are suitable for flood protection and can be equated with sandbagging in terms of functionality (cf. Pinkard et al., 2007; Niedersaechsischer Landtag, 2014; Massolle et al., 2018). The effectiveness of the individual system might differ depending on construction, geom- 
etry and filling. Nevertheless, decision makers need to have reliable information about the general functionality of an individual SBRS. This information is not always available, especially not from an independent source.

Sandbagging is time-consuming as well as highly intensive with respect to materials and personnel. SBRSs have the potential to be much more efficient flood defences as their use entails significantly lower material, personnel and time requirements than conventional sandbagging. For example, 16500 sandbags and $250 \mathrm{t}$ of sand are required to build up a $100 \mathrm{~m}$ long and $1.0 \mathrm{~m}$ high sandbag dam (cf. THW, 2017). Without considering additional efforts, such as the logistics of supplying materials and personnel, 60 helpers would take about $10 \mathrm{~h}$ to fill the sandbags and set up the dam (cf. THW, 2017). However, the advantage of using sandbags lies in the possibilities for flexible deployment and many years of practical experience. Figure 2 shows firefighters raising a dike by setting up a temporary sandbag dam.

SBRSs either do not need a filling at all or the filling is put in place with technical assistance such as pumps (water filling), wheel loaders (sand filling) or cranes (bulk elements made of concrete). Thus, the systems can be set up and dismantled with considerably less time and fewer people (cf. Massolle et al., 2018). Logistical efforts are minimised if no filling is needed or if water, which can usually be obtained locally, is used. In contrast to sandbags, SBRSs are reusable and do not have to be disposed of at high cost after a flood event. From these points of view, SBRSs can also be suitable for scheduled flood protection measures in areas where no permanent flood protection schemes can be applied. The main disadvantage of SBRSs is the higher cost of acquisition. However, the lower expenditure on helpers, logistics and disposal of material means that these higher investment costs can be offset through reuse. Furthermore, there is limited confidence in and a lack of knowledge of the functionality of SBRSs. Besides the low confidence in the general functionality of an SBRS, possible vandalism or mechanical influences, e.g. the impact of flotsam or vehicles as well as the collective failure (causing a domino effect) of SBRSs, are of great concern. In general, the functionality of sandbag dams can also be endangered by vandalism or mechanical influences but rather less by a collective failure, unless the sandbag dam heavily overflows with the flow travelling over long distances.

Temporary flood dams made out of sandbags or linear SBRSs are set up in order to protect the hinterland from inundation. Beyond that, sandbags are also used on inner embankments, securing saturated dikes either on selected points where there is considerable seepage (using a temporary ring dam) or over a larger area (using a load drain). Flutschutz offers corresponding SBRSs (Fig. 3). See Simm at al. (2013) for an explanation of the hydraulic situation at saturated dikes during a flood event. Sandbag dams and linear SBRSs are directly exposed to flooding. In contrast, temporary ring dams and load drains are generally exposed to lower loads as they are not subject to the direct influence of high hydrostatic pressures or the dynamic impact caused by waves and flotsam. They are therefore less endangered in terms of their functionality.

In Germany, operational flood defence is regulated as part of hazard prevention or disaster control at the federal state level. Direct responsibility lies at the municipal level and thus with the local districts and cities. This includes the responsibility of providing the necessary material for the protection of the general public, and sandbags - which are the significantly cheaper option - are as a rule preferred over SBRSs. In the case of a disaster event, assistance can be requested from the federal state or the federal government although the financing of such assistance will still remain initially with the affected administrative districts or cities. Ultimately, the costs of major damage events, such as those caused by the Elbe floods of 2002, 2006 and 2013, will be borne predominantly by the federal state and the federal government. Once such an event occurs, however, no time can be lost in procuring SBRSs if they are not already standing by. Thus, the cost of procuring and stocking SBRSs, in addition to a lack of confidence in or knowledge about their functionality, presents a major hurdle to their use.

Therefore, in Germany during the Elbe flood in 2013, SBRSs were only used in isolated cases (AQUARIWA, 2019; Mobildeich, 2019) despite the fact that the use of sandbagging for operational flood defence is very time-, materialand labour-intensive. Figure 4 shows two SBRSs after the Elbe flood in 2013. The two systems were successfully used to prevent the hinterland from flooding (Niedersaechsischer Landtag, 2014).

In order to increase the confidence of decision makers in SBRSs and to promote the availability of only wellfunctioning SBRSs, it is desirable to carry out systematic tests on functionality, stability and handling and to develop relevant certification procedures. In addition to the functionality of SBRSs, their costs and efficiency in terms of personnel, time and logistics compared to sandbagging should be investigated to likewise support decision makers.

At the international level, corresponding certification already exists. It can be awarded by the globally active testing and certification service, FM Approvals (FM Approvals, 2019), based on the American National Standard for Flood Abatement Equipment (ANSI and FM Approvals, 2014), and by the British Standards Institution (BSI, 2019a) based on the Publicly Available Specification (PAS) for flood protection products (specification type 2, temporary and demountable flood protection products; BSI, 2014). Specific SBRSs certified by FM Approvals can be found via the National Flood Barrier Testing \& Certification Program (NFBTCP, 2019), and SBRSs certified by the BSI Kitemark can be found via the BSI (BSI, 2019b). In Germany, no corresponding certification or testing system for SBRSs is currently available. However, some information can be found on the design and both the scheduled and unscheduled use of 
Mobile flood protection systems/Location-independent mobile systems

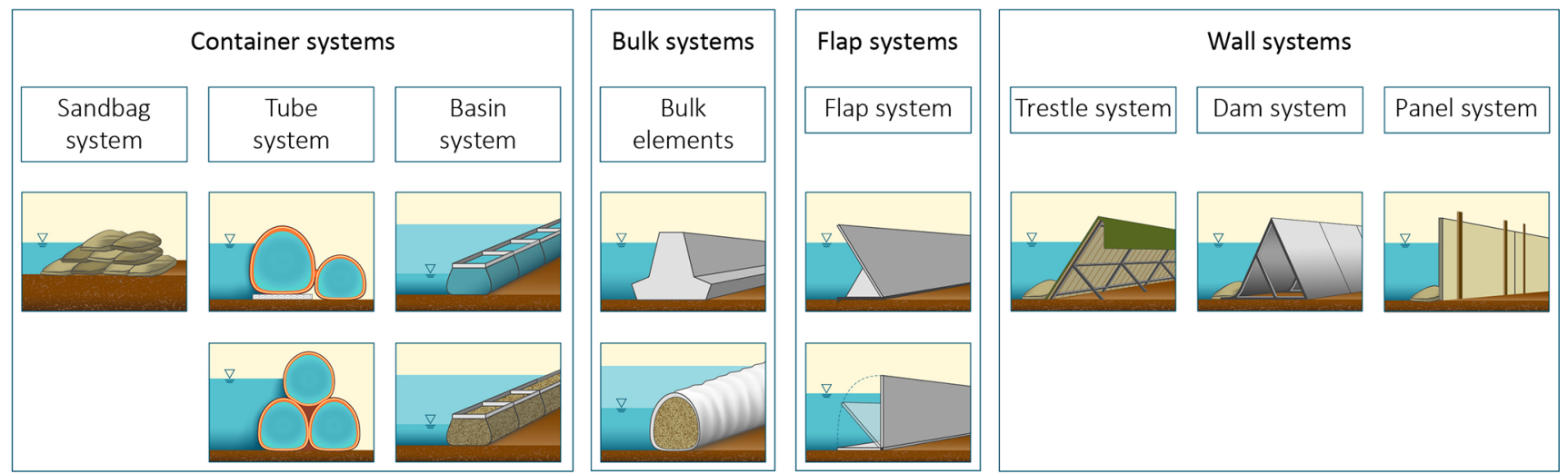

Figure 1. Classification of mobile, location-independent flood protection systems (Massolle et al., 2018).

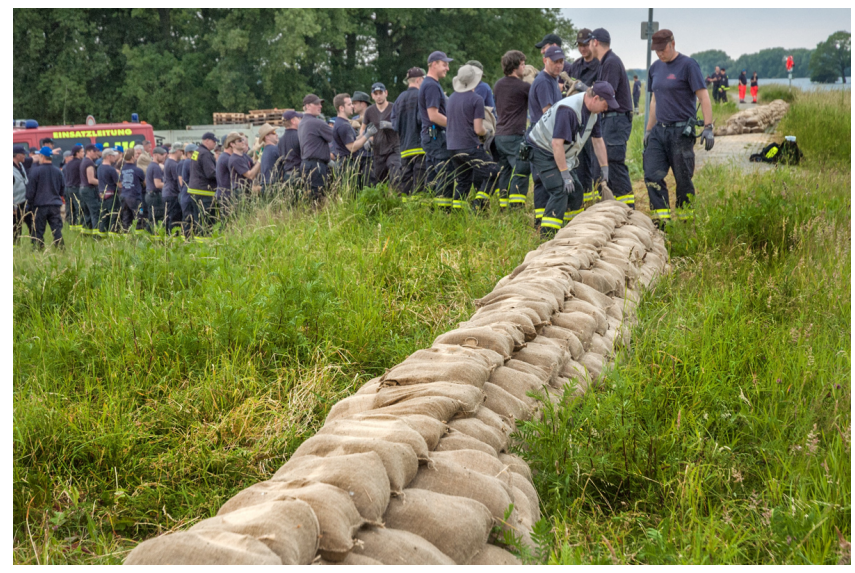

Figure 2. Firefighters during the Elbe flood in 2013, setting up a sandbag dam to raise a dike.

SBRSs in German-speaking countries, especially in the recommendations of the leaflet Mobile Flood Defence Systems, issued by the German Association of Engineers for Water Management, Waste Management and Cultural Construction (BWK, 2005), in the handbook Mobile Flood Protection, issued by the Austrian Water and Waste Management Association (ÖWAV, 2013), and in the decision-making aid Mobile Flood Protection, issued by the Swiss Association of Cantonal Fire Insurers and the Swiss Federal Office for Water and Geology (VKF and BWG; see Egli, 2004).

There are relatively few publications on comparative studies of sandbagging and SBRSs. Within the scope of test setups in the test basin of the US Army Corps of Engineers (USACE), one sandbag dam, two sand-filled container systems and one trestle system were investigated (Pinkard et al., 2007). In addition to the time spent on system installation and dismantling, the operational costs of a system set-up with a length of around $305 \mathrm{~m}$ and a height of around $0.91 \mathrm{~m}$ were also estimated. However, logistical aspects were not taken into account, and it was assumed that labour on the construction of the sandbag dam would be free on a voluntary basis. In addition, the sandbag requirement estimated in the study differs from the usual approaches in Germany as sandbag dams in the US are constructed on a broader basis.

Investigations into the functionality of SBRSs were also carried out by the UK Environment Agency (EA; Ogunyoye et al., 2011) on the basis of three sources of information: the literature, user workshops, and interviews with manufacturers and distributors of products. It was found that most of the systems provided adequate protection but that in some cases operational processes or inaccurate hydraulic assessments led to system failure. The assessments covered the physical, operational and structural characteristics of temporary flood products available on the UK market in 2009. The systems were subdivided into tubular systems, containers, freestanding barriers and frame barriers. The report furthermore highlights the relevance of life cycle costs when using SBRSs. In addition to the acquisition costs, these include costs of maintenance and repair of the systems, employment costs (in the investigation the helpers were permanently employed), training costs, costs of the performance of field exercises, and costs of the storage and transport of the systems. A benefit of an SBRS, on the other hand, is the prevention of damage costs during its service life when a properly functioning system is assumed. An example calculation of the life cycle costs of an SBRS is not carried out in the report. Only the acquisition costs of SBRSs, partly including the training of helpers (employees) by the manufacturers, for a $100 \mathrm{~m}$ long system with a protection height of about $1.0 \mathrm{~m}$ across the four categories examined - tubes, containers, freestanding barriers and frame barriers - are mentioned.

In a Canadian study that assessed the suitability of innovative systems as an alternative to sandbags primarily on the basis of the literature, commercial brochures, theoretical con- 

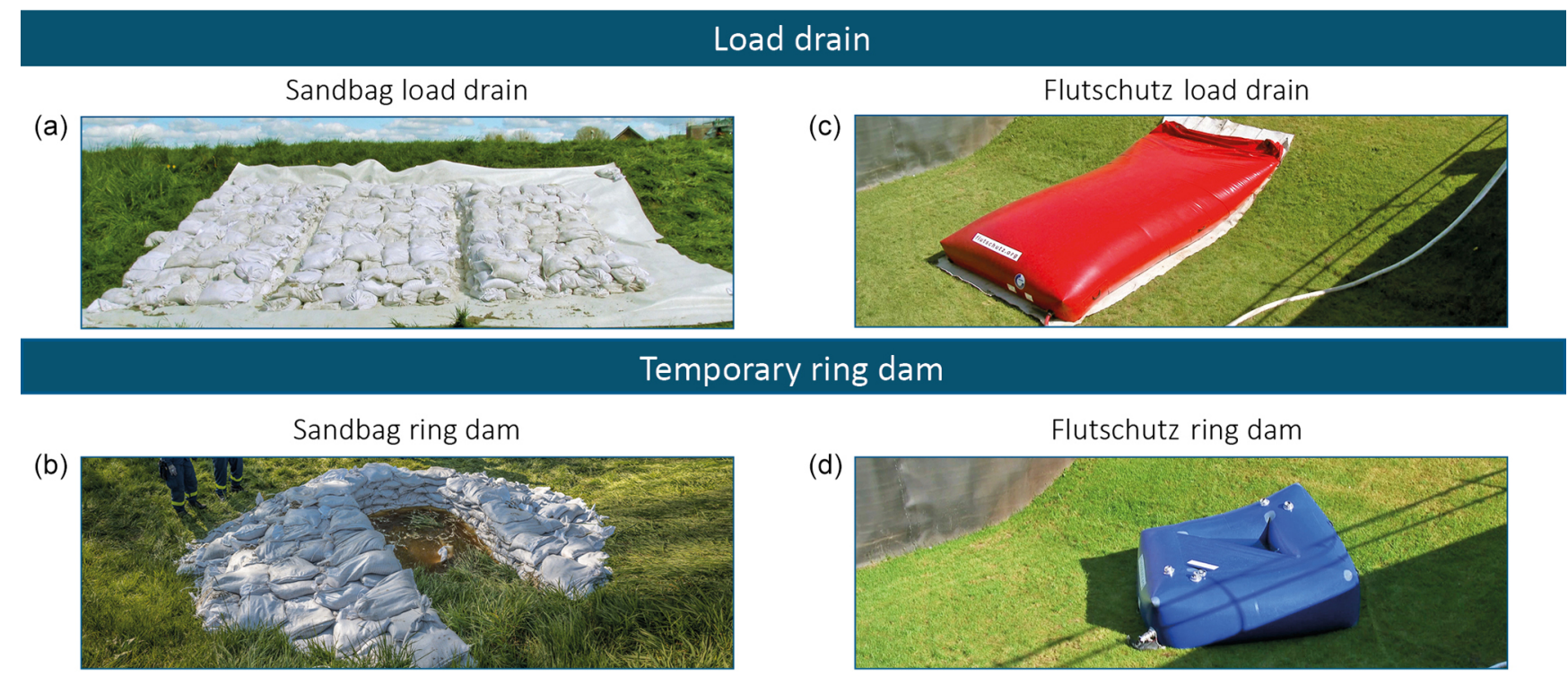

Figure 3. Dike defence measures for a saturated dike over an extensive area (load drain) and for heavy punctual seepage discharge (temporary ring dam). Sandbagging systems (a, b) and corresponding SBRSs (c, d) are shown.
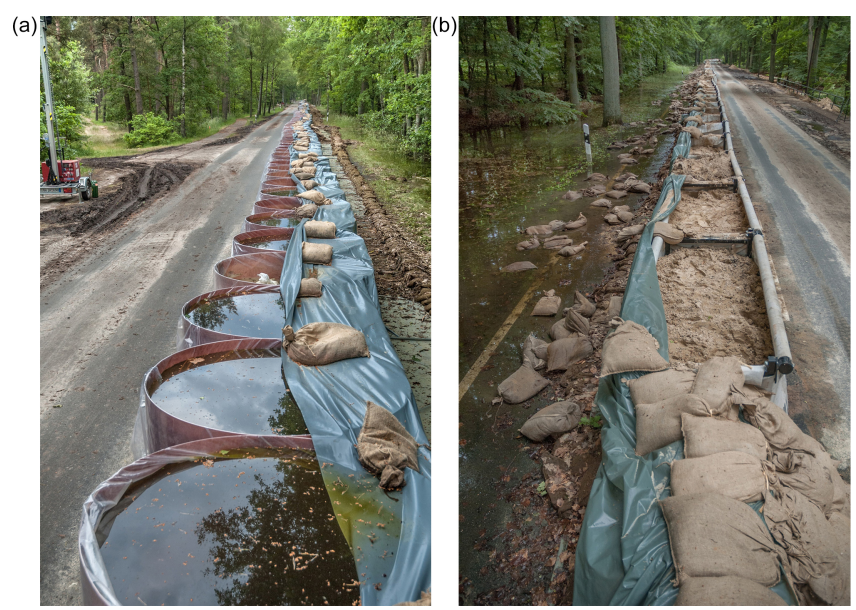

Figure 4. SBRSs near Gartow (Lower Saxony, Germany) after the Elbe flood in 2013 using (a) AQUARIWA and (b) Quick Damm Type E.

siderations and stability calculations, four different system types were examined. The types studied were water- or airfilled tube systems, gabion-like systems filled with sand or soil, dam beams, and motorway crash barriers. Besides assessing the functionality of the systems, the factors to be considered for a cost calculation of SBRSs are named, but no comparative calculations are carried out. The stated costs refer to manufacturers' prices for a system with a protection length of $30 \mathrm{~m}$ and a protection height of about $1.0 \mathrm{~m}$. The additional financial resources to be considered include costs of the storage, assembly and dismantling of the systems as well as of training the helpers. Moreover, the durability of the systems must also be taken into account as a long service life has a positive effect on the number of times a system can be reused (Biggar and Masala, 1998)

In a study conducted by the University of Kentucky (McCormack et al., 2012), the possible uses of sand-filled temporary flood defence barriers to protect roads from flooding were analysed on the basis of existing operational experience. However, the systems considered are not comparable with those covered in the present study.

In Germany SBRSs have been tested according to ANSI and FM Approvals guidelines at the Centre for Climate Impact Research (KLIFF) at the Hamburg University of Technology (TUHH) on concrete ground (Gabalda et al., 2013). The tests were mainly performed on behalf of the manufacturers, who have published the information only sporadically (cf. Massolle et al., 2018). Recently Popp et al. (2019) theoretically investigated the functionality and related costs of SBRSs in comparison to sandbagging when used to temporarily increase the height of a dike. Their investigations do not relate to individual SBRSs but rather to different system types (tube, basin and trestle). However, it is not clear what was included in the cost calculation. They conclude that SBRSs will be used more frequently in the future to temporarily raise the height of a dike because of the reduced requirements of SBRSs in terms of time, materials and personnel.

None of the examples mentioned in the literature examined the functionality or costs of temporary ring dams or load drains.

SBRSs can make an essential contribution to operational flood defence owing to their functionality, time-saving characteristics, and lower requirements for materials and person- 
nel. This contribution becomes even more pertinent in view of the expected consequences of climate change. However, only a small amount of information is available on independent, practical tests of SBRSs. For some SBRSs, no practical or independent tests are available at all, and a comparative study of the overall costs of sandbagging and SBRSs is entirely missing. Both factors - functionality and economic viability - are especially relevant to decision makers for assessing the suitability of using SBRSs, which introduce great potential to make operational flood defence measures, especially for disaster management, much more efficient in terms of time, personnel and materials. It was therefore decided that systematic testing of SBRSs would be carried out in the test facility of the Institute for Hydraulic and Coastal Engineering (IWA) at the City University of Applied Sciences, Bremen, Germany, to increase the amount of available information on the functionality of SBRSs. The focus of the test set-ups was on the functionality and stability as well as the handling of the systems tested. The first results of the test set-ups with regard to installation times, water heads and seepage rates were published in Massolle et al. (2018). The present article summarises the experience gained from the test set-ups with regard to the functionality, stability and handling of the individual systems in accordance with the guidelines for loss prevention issued by the German Insurers for Mobile Flood Defence Systems (VdS Schadenverhütung $\mathrm{GmbH}, 2014)$, which are in turn based on the recommendations of the BWK (BWK, 2005), the VKF and the BWG (Egli, 2004). The system assessments obtained in this way serve to provide a practical assessment of the operational capability of SBRSs. Furthermore, the present article compares sandbagging with SBRSs in fictitious realistic scenarios in order to enable a comparison of the costs surrounding system deployment, the time involved and the number of helpers. The comparison serves to further clarify the practical suitability of SBRSs and, in addition to the acquisition costs, takes into account the costs, efforts and logistics of installing and dismantling the systems. In addition to a temporary flood protection dam, appropriate dike defence measures for operational flood defence (load drains and ring dams) are also considered. The calculated operational costs always depend on the underlying system model or the dimensions of the sandbag system as well as other factors. This necessarily calls for a certain degree of simplification, resulting in deviations between the findings of the above-mentioned studies by Pinkard et al. (2007) and Ogunyoye et al. (2011) and the present study.

\section{Sandbag replacement systems and equivalent sandbagging methods}

The investigations described here focus on the following three operational flood protection measures: (1) temporary flood dams, (2) load drains applied to a saturated dike over an extensive area and (3) ring dams used for reinforcement against heavy punctual seepage discharge on the inner embankment of a dike. The classic aid for constructing these measures are sandbags. Sandbagging has proven itself during many years of application. Sandbags are made out of jute or plastic, are not standardised in size, and cannot be reused once they have been used in a flood event. Especially for long and/or high protection structures, a multitude of bags and a large amount of sand is required. If stored properly, filled sandbags have a maximum shelf life of 5 years. If unfilled, they can be stored for up to 10 years. However, it should be noted that the shelf life of filled sandbags may be severely limited if they are stored under poor conditions. When stored outdoors, sandbags can become so decomposed that they are no longer fit for use after only a few months. Sandbags are usually stored unfilled, thereby giving them a longer shelf life. In principle, this also minimises logistical efforts because it is easier to transport large numbers of sandbags and large amounts of sand separately.

In case of a flood event, sandbags and/or sand need to be transported to the scene of the flooding and, if necessary, the sandbags are filled either manually with, for example, shovels or with the aid of sandbag-filling machines. The filled sandbags are transported to the flood defence line with vehicles or, if accessibility is limited owing to, for example, a poor subsoil situation, with the help of human chains, helicopters or boats. If applicable, the sandbags have to be unloaded after transportation and are put in place individually. Altogether, these steps result in significant logistical efforts, personnel requirements and time demands.

The construction of the three operational flood protection measures with sandbags is not standardised; slightly different techniques and quantities of sandbags might be used. However, in principal the following structures are used: (1) the temporary flood dam is a trapezium-shaped sandbag dam that sets up a temporary flood protection line, (2) the load drain is layers of sandbags that place additional weight on the toe of a dike and (3) a U-shaped or circular dam is used to dam up punctual seepage through the inner embankment of a dike.

SBRSs on the other hand require much less logistical effort and time and many fewer personnel mainly because the systems consist of larger units which are either not filled at all or filled by technical means. Furthermore, the filling material of water can often be obtained directly at the flood defence line. Unlike sandbags, SBRSs hold potential for subsequent reuse during their service life. In the case of SBRSs, the guarantee period specified by the manufacturer must be compared to the actual shelf life. Inquiries to manufacturers have shown that not all producers give a guarantee or that the guarantee often only amounts to a few years. When interviewed, however, some manufacturers stated that the service life of demonstration models reached 10 years or more. Considering the materials used in the production of the SBRSs, such as tarpaulin fabric, galvanised steel or fibreglass-reinforced 
plastic, it can certainly be assumed that an SBRS can have a service life of 10 years or more.

Table 1 gives a short description of the systems investigated, and Fig. 5, as well as Fig. 3, shows the SBRSs tested in the testing facility. At least one of the container types and wall systems shown in Fig. 1 was selected for each of the test set-ups. Flap systems could not be tested because no manufacturer was found who was prepared to provide their system for the tests. Bulk elements and panel systems were not considered because in operational practice the use of bulk elements requires technical aids being available to install the elements at short notice. This is often impractical for logistical reasons or because the load-bearing capacity of the foundation soil is impaired during flooding. The use of panel systems is limited to suitable soils and low water levels. Bulk elements and panel systems, with their framework conditions such as accessibility for heavy equipment and the avoidance of damage to test set-ups from the deep ramming of retaining stakes, were therefore not taken into account.

For a comparison of the functionality, stability and handling of the different systems, a $0.8 \mathrm{~m}$ high and $2.1 \mathrm{~m}$ wide sandbag dam was set up in the test facility (Fig. 6); see Massolle et al. (2018) for further details. In addition to the linear SBRSs, a Flutschutz load drain and Flutschutz ring dam were set up on the embankment of the dike in the test facility (see Fig. 3). The systems were set up on the dry and therefore stable dike, which does not fully correspond to the reality. The systems' dimensions and further properties of the SBRSs tested are shown in Table A1. For assembly instructions, please refer to the manufacturers' home pages.

In cases where the suppliers offered more than one system size, a variant suitable for a water head of $0.6 \mathrm{~m}$ was selected for the test set-ups. This height corresponds to the recommendations contained in the technical bulletin Mobile Flood Protection Systems (BWK, 2005) for the unscheduled use of SBRSs in operational flood fighting. The height recommendation results from the increasing danger of foundation surface failure with increasing water levels. Not exceeding the specified maximum water level minimises the risk of base failure. If larger system heights are required, the risk must be weighed on a case-by-case basis. The problem is that, even if a foundation expert is available on site during the flood event, time pressures and limited information on soil parameters do not allow for an accurate analysis. Since some systems are not specifically designed for water heads of $0.6 \mathrm{~m}$, systems with surplus dimensions, such as AQUARIWA, aqua defence, Hydrobaffle and Tiger Dam, were used.

The SBRSs tested are only a selection of the systems available on the market. In addition, one of the systems investigated, the Quick Damm Type M, is no longer produced but still in use. Market analysis showed that some system types, such as basin systems and tube systems, are more frequently present on the market than others. However, the number of products available of a particular system type does not allow for conclusions to be drawn about its functionality.
Tube systems and basin systems are usually filled with water to ensure their stability; not many tube or basin systems can be filled with sand. Sand fillings were not considered during the test set-ups as the filling and dismantling requirements could not be met in the test facility. Therefore, tube and basin systems filled only with water were tested. The Öko-Tec tubewall is an exception. With this system, the tube is inflated with air. The system is stabilised by a plastic sheet called a skirt, which is spread out on the water side of the system and friction locked to the tube. The tube is stabilised solely by the vertical hydrostatic pressure acting on the horizontally laid skirt. None of the other tested systems using a plastic tarpaulin as an upstream skirt used such friction locking. A non-friction-locked skirt is mostly used to improve the leak tightness of an SBRS, which also reduces buoyancy forces under the SBRS. An upstream skirt must always be weighted down at the water-side edge, often with sandbags. The trestle and dam systems do not require filling.

\section{The functionality, stability and handling of the SBRSs tested}

\subsection{Description of the test}

The tests were carried out in the IWA test facility, which was set up on the premises of the THW Training Centre Hoya as part of the research and development project, DeichSCHUTZ (2014-2017), for the development of systems to reduce buoyancy in dikes at risk of failure, funded by the German Federal Ministry of Education and Research. The facility consists of a U-shaped basin in which a $15 \mathrm{~m}$ wide opening is closed by a dam (see Massolle et al., 2018). For the SBRS tests, the systems were set up across the entire width of the basin, parallel to the dam line and the space between the dam, and the system was then filled with water (Fig. 7). This allows for a realistic simulation of the hydrostatic load on the systems. Other possible load parameters such as current, waves, wind, flotsam and vessel impact cannot be investigated in the IWA test facility.

During the test set-ups, the systems impounded water. Water heights were increased successively until system failure occurred. Typical failure mechanisms of SBRSs are shown in Fig. 8. The systems failed owing to sliding and rolling or tipping; stability failure did not occur in any of the systems tested. If no system failure occurred, the systems were made to not only impound as much water as possible but also overflow. Seepage rates, the sum of seepage through the subsoil and leakage through the system, were measured, and the results were published in Massolle et al. (2018). An SBRS should be not only functional but also practical in many respects; considerations include handling during setup, dismantling, the space required during both operation and storage, reusability, and protection against vandalism. Altogether, statements about the reliability as well as the prac- 
Table 1. Short description of the SBRSs tested.

\begin{tabular}{|c|c|}
\hline Product name & Description \\
\hline \multicolumn{2}{|l|}{ Basin } \\
\hline AQUARIWA & $\begin{array}{l}\text { Plates bend to cylindrical basins. If filled with water (other filling materials are possi- } \\
\text { ble), water sacks within the basins are necessary. The bottom of the basin is covered } \\
\text { with a plastic grid which is welded to the plates in order to increase the stability of the } \\
\text { basins. Spaces between the basins are sealed with a plastic tarpaulin which is weighed } \\
\text { down with sandbags. }\end{array}$ \\
\hline INDUTAINER & $\begin{array}{l}\text { A basin with plastic sacks filled with water. The upper end is tied up. The basins are } \\
\text { connected to each other with wooden scantlings. The space between the basins is sealed } \\
\text { with a plastic tarpaulin which is weighed down with sandbags. }\end{array}$ \\
\hline Quick Damm Type M & $\begin{array}{l}\text { Open, collapsible steel frame with a plastic basin filled with water. Spaces between the } \\
\text { basins are sealed by the system itself. }\end{array}$ \\
\hline \multicolumn{2}{|l|}{ Trestle } \\
\hline Aqua defence & $\begin{array}{l}\text { Hard foam panels covered with plastic tarpaulin on collapsible support elements. The } \\
\text { tarpaulin is weighed down with sandbags. }\end{array}$ \\
\hline Aqua Barrier & $\begin{array}{l}\text { EUR-pallets covered with plastic tarpaulin on collapsible support elements. The } \\
\text { tarpaulin is weighed down with sandbags. }\end{array}$ \\
\hline \multicolumn{2}{|l|}{ Dam } \\
\hline NOAQ boxwall & $\begin{array}{l}\text { Plastic brackets inserted into each other and connected on the top side with a clamp. } \\
\text { The underneath is sealed with a thin strip of foam on the water side and shaped in a way } \\
\text { that any water under the system can run off to the air side. }\end{array}$ \\
\hline \multicolumn{2}{|l|}{ Tube } \\
\hline Tiger Dam & $\begin{array}{l}\text { Closed, water-filled system, strapped into a pyramid shape and secured with wedges. } \\
\text { The joints are sealed with a sleeve. Use of a plastic tarpaulin and anchoring to the } \\
\text { ground are possible. }\end{array}$ \\
\hline Hydrobaffle & $\begin{array}{l}\text { Closed, water-filled system with an intermediate baffle to prevent rolling. The system is } \\
\text { laid to overlap at the joints. }\end{array}$ \\
\hline Mobildeich & $\begin{array}{l}\text { Closed, water-filled system held together in two- to three-tube packages with net sheath- } \\
\text { ing and sealing tarpaulin. The tarpaulin is weighed down with iron chains. A geotextile } \\
\text { is placed below the tubes. }\end{array}$ \\
\hline $\begin{array}{l}\text { Flutschutz double- } \\
\text { chamber tube }\end{array}$ & $\begin{array}{l}\text { Closed, water-filled system with two tubes of different diameters. The tubes are welded } \\
\text { together in order to prevent rolling. A sealing mat is placed below the upstream tube. } \\
\text { Spaces between the tubes are sealed by the system itself whereas the joints are secured } \\
\text { with a rope. }\end{array}$ \\
\hline Öko-Tec tubewall & $\begin{array}{l}\text { Closed air-filled system with a welded upstream skirt and plastic grid. A drainage mat } \\
\text { is placed at the bottom between the skirt and grid. The skirt is weighed down with lead } \\
\text { belts. }\end{array}$ \\
\hline \multicolumn{2}{|l|}{ Load drain } \\
\hline Flutschutz load drain & Closed, water-filled basin. A drainage mat is placed below the system. \\
\hline \multicolumn{2}{|l|}{ Temporary ring dam } \\
\hline Flutschutz ring dam & Closed, water-filled tube with a triangular stabilising canvas welded to the tube. \\
\hline
\end{tabular}


Flutschutz double-chamber tube (T)

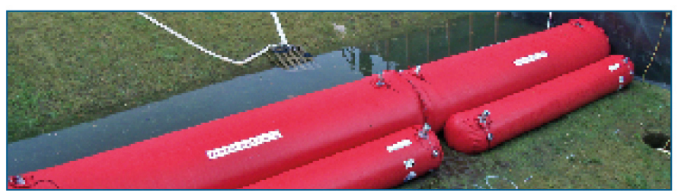

Mobildeich (T)

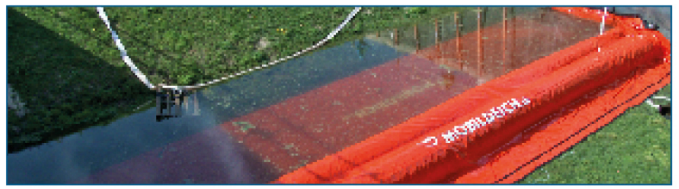

Tiger Dam (T)

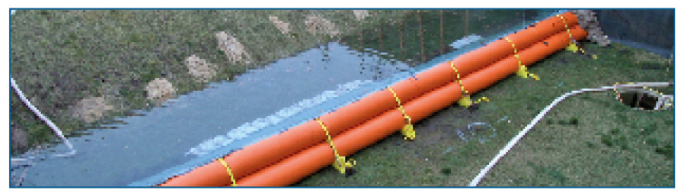

INDUTAINER(B)

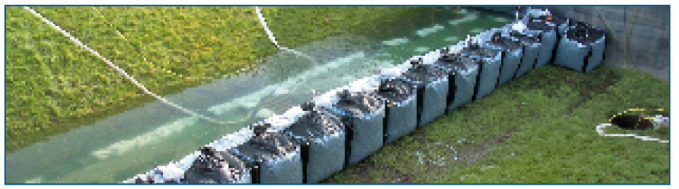

NOAQ boxwall (D)

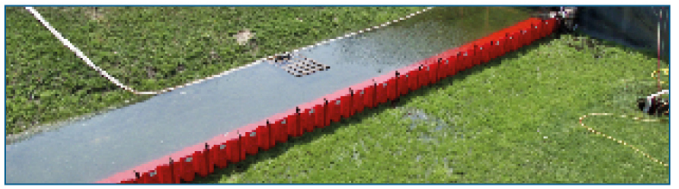

Quick Damm M (B), AQUARIWA (B), Aqua Barrier (TR)

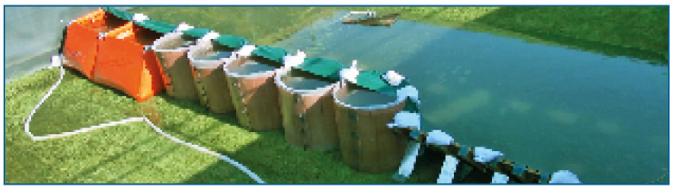

Figure 5. The various SBRSs tested. (T) is tube system, (B) is basin system, (D) is dam system and (TR) is trestle system.

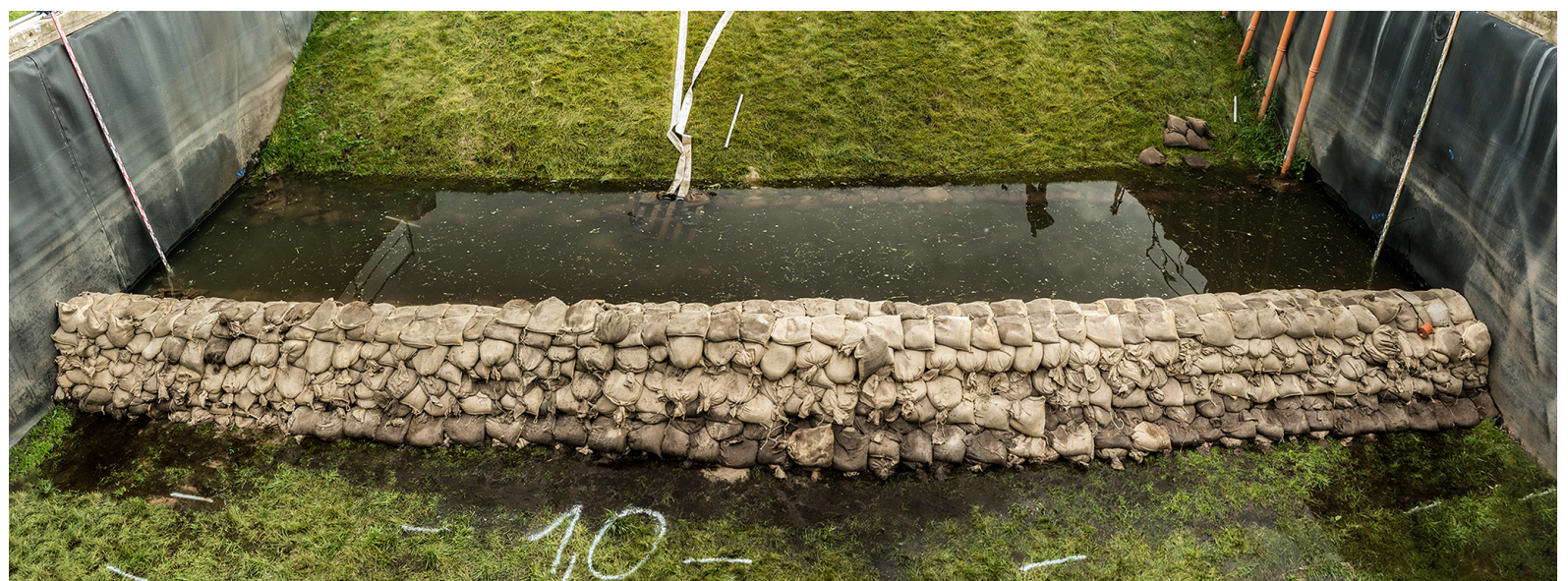

Figure 6. Sandbag dam in the IWA test facility. 


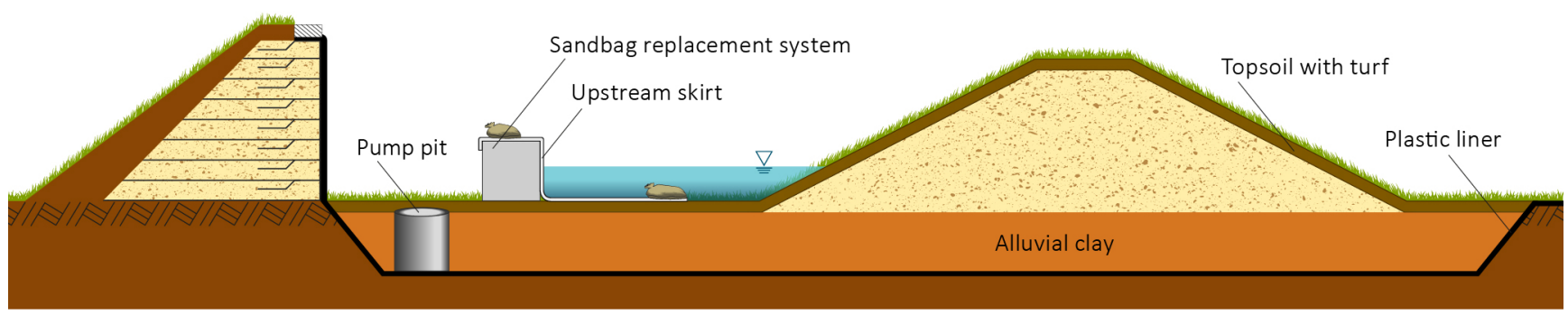

Figure 7. Illustration of the test set-up in the test facility. An SBRS with an upstream skirt is shown.

ticality and handling of the systems tested could be derived from the test set-ups and related investigations.

The systems were initially dammed up to a water height of $0.6 \mathrm{~m}$, in accordance with the recommendations of the BWK leaflet Mobile Flood Protection Systems (BWK, 2005). After setting a constant seepage rate at a dam height of $0.6 \mathrm{~m}$ (see Massolle et al., 2018), the water head was further increased in stages until a system failure occurred owing to the water height exceeding the load limits of the system or until a partial overflow of the system occurred. See Massolle et al. (2018) for an overview of the system heights and the impounded water levels achieved. The Quick Damm Type M and Aqua Barrier systems were not available in a sufficient length and were therefore installed in combination with the AQUARIWA system. The test basin was only briefly filled with water up to a height of $0.6 \mathrm{~m}$. The NOAQ boxwall system only has a feasible protection height of $0.5 \mathrm{~m}$ but was nevertheless tested because of its simplicity and speed of installation. In principle, the manufacturer recommends the use of the NOAQ boxwall system on paved surfaces as this results in a better sealing effect on the underlying surface. According to the manufacturer's training material, the Tiger Dam system can be used with or without anchoring to the ground and additional plastic skirts on the water side, but it only qualifies for FM Approvals certification if the skirts and the anchoring system are in place (NFBTCP, 2019). Both variants were investigated. The tightening belts pulled around the tubes were fastened on every second wedge with a rope affixed to stakes on the land side and water side. Finally, a plastic skirt was spread in front of the system on the water side, which reached up to the apex of the upper tube.

Full impoundment of water in the systems tested and water overflow cannot be realised over the entire length of the SBRSs owing to unevenness of the basin floor and limited pumping capacity in the IWA test facility. This restriction is particularly relevant in cases when an overflow load occurred as the unevenness meant that only a slight overflow height could be achieved in the right-hand area of the test facility (Fig. 9).

If overflow occurs when using SBRSs, it must be prevented from washing away the soil on the land side, other- wise system failure can occur. The overflowing water must be discharged or distributed over a sufficiently large area. Theoretically, an SBRS can overflow if the system is sealed via vertical water pressure since with increasing water levels the system is increasingly stable via the vertical pressure. A protruding skirt on the water side will afford more protection as the buoyancy forces under the system are thereby minimised. Whether the system will overflow depends on its geometry and/or bulk. With increasing water levels, the probability of failure due to tilting, slipping or rolling increases. Systems that do not benefit from the stabilising effect of vertical water pressure are not stabilised further with an increasing water level. In terms of stability, a large bulk and/or a low centre of gravity are fundamentally advantageous here. The tests do not take into account the possibility of the foundation soil giving way with increasing water levels since damming within the test set-ups only took place on a defined and stable floor. However, especially at high water levels, underground failure can be an important source of failure.

\subsection{Test results}

The systems were tested on a grass surface and were set up by two people. In some cases, there were major differences between the manufacturer's time specifications and the times measured during the test set-ups (Massolle et al., 2018). To be set up, the systems had to be transported manually from the edge of the basin to the point of installation and thus over a maximum distance of $15-20 \mathrm{~m}$. It is quite conceivable that faster installation times can be achieved on surfaces suitable for vehicles and which offer better logistical conditions. On the other hand, significantly longer manual transport distances - and thus longer assembly times compared to the test conditions - may occur in practice. The installation times for the water-filled SBRSs also depend strongly on the available pump capacity and the water supply. In principle, however, it can be said that the installation and dismantling of the systems is generally possible with just two people and is many times faster than the construction of a sandbag dam. In addition, it is also possible to optimise installation times by using more helpers. Systems that have no filling require- 


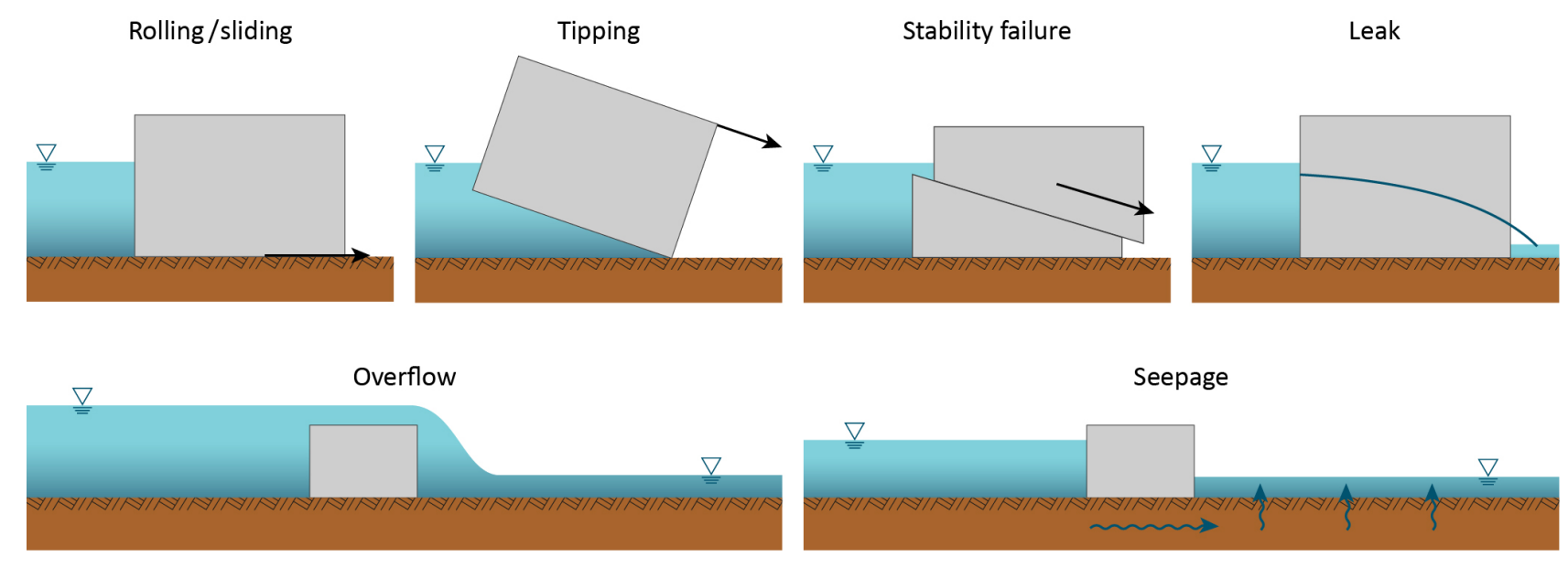

Figure 8. Typical failure mechanisms of SBRSs (BWK, 2005, modified).

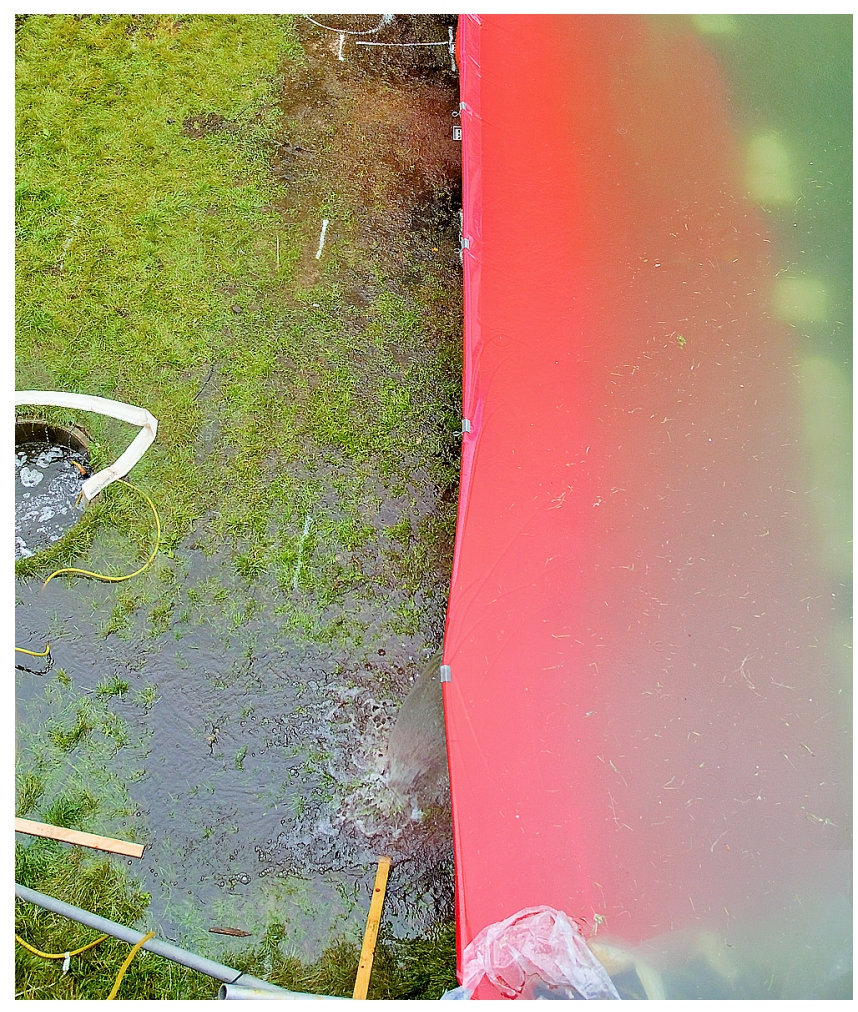

Figure 9. An overflowing SBRS (aqua defence).

ment also show a clear time advantage during assembly and dismantling.

Setting up the systems is often self-explanatory, and instructions are easy to follow. It is still recommended, however, to involve an expert in order to avoid possible assembly errors which could have far-reaching consequences. With the Öko-Tec tubewall system, for example, there is a risk that the drainage mat located under the upstream skirt will become inverted, thus endangering the functionality of the system.

Taking precautions against buoyancy can be generally recommended. Systems such as the NOAQ boxwall, Tiger Dam or Öko-Tec are dependent on this safety precaution. Protection can be ensured by an upstream skirt, a drainage system, a seal on the water-side edge or anchoring of the system. Systems such as the Flutschutz double-chamber tube (DCT) have good protection against failure owing to the buoyancy afforded by their high bulk weight, and no further measures are called for. However, completely weighting down an upstream skirt with sandbags or other weights is still generally recommended as this can also considerably minimise the occurrence of seepage (see Massolle et al., 2018).

Systems with a restricted contact surface (aqua defence, Aqua Barrier and Tiger Dam) are especially prone to the danger of sinking into saturated ground. This risk also applies to the AQUARIWA system, the filled base of which is flat but whose plastic skin lies somewhat unevenly. Precise data on how long it would take for the system to fail due to sinking at the contact surfaces cannot be derived from the test carried out, owing to the test's relatively short duration of just a few hours (Massolle et al., 2018). In principle, there is a correlation between the depth of subsidence, the magnitude of the load exerted, the type and the antecedent wetness of the ground underneath, and the duration of a flood event, which can last up to several days or even weeks. Some subsidence of the systems with a restricted contact surface could be observed during water impoundment, but this did not lead to failure during the test set-ups presumably because of the short damming time of just a few hours. Figure 10 shows the aqua defence system during dismantling. The system sank the most deeply into the foundation soil in the area of the greatest water depths during damming, seen at the top of Fig. 10. In this area, however, the system also overflowed while the test basin was being filled with water, so some of 


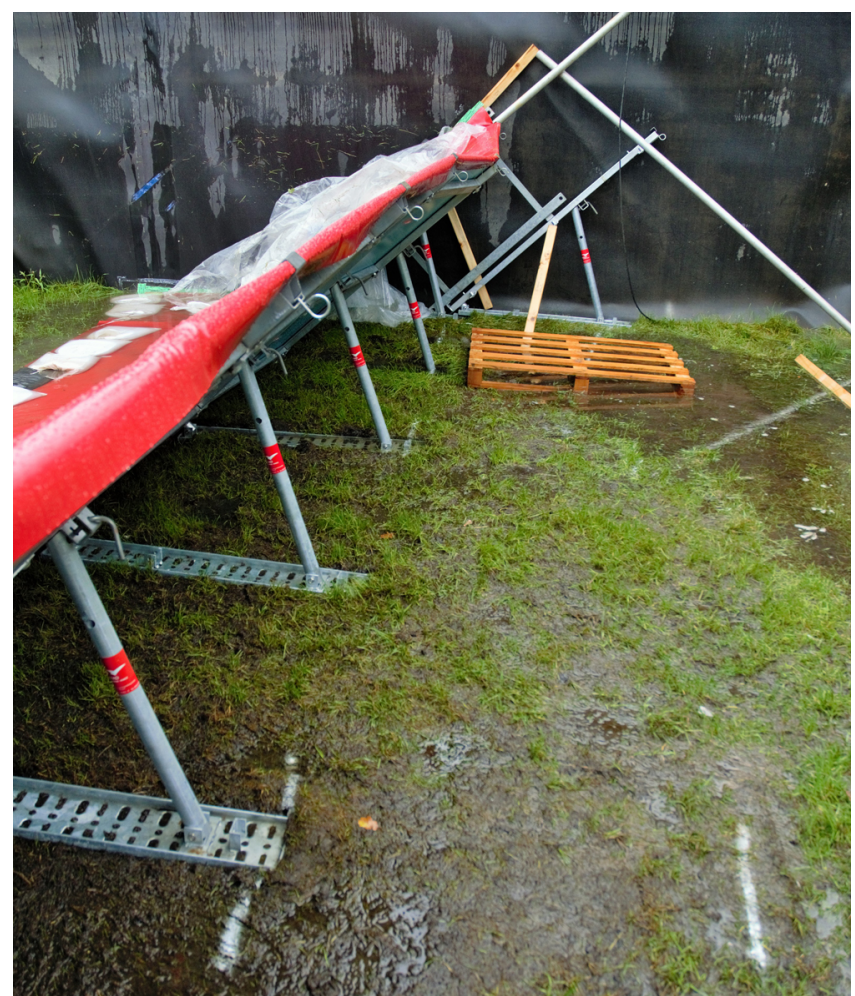

Figure 10. Supporting columns sunk into the saturated foundation soil after damming (aqua defence).

the increased subsidence was probably due to erosion of the foundation soil.

Particularly in the case of fine sandy soils, there is a risk of foundation soil failure owing to hydraulic heave or erosion caused by water flowing under the system. Especially when additional pumping is used, care must be taken that the soil under the systems is not removed with the flow of water being pumped out. There is also a risk that the friction between the soil and system on paved ground will be reduced by the presence of loose grains of sand or gravel. In these cases, sweeping the areas around the contact surfaces prior to installation is recommended. Minor unevenness can be levelled out with sandbags or with lime that swells on contact with water. When installing the systems, attention must be paid to whether there are gradients in the terrain across or along the planned system line as this would increase the risk of tipping, sliding or rolling. Some systems (Flutschutz DCT, Hydrobaffle, Tiger Dam and Aqua Barrier) shifted or were deformed when the test basin was being filled with water, owing to flexibility in their construction or expansion of the material they are made of, but then stabilised again. The pending failure of all the systems when overloaded was always indicated by visible shifting, but this indication usually happened so quickly that there was no possibility of taking countermeasures over longer periods.
In terms of seepage rates, the tested systems are either comparable to a sandbag dam or to a sandbag dam with a protruding plastic skirt (Massolle et al., 2018).

In summary, it can be stated that all the systems tested remained stable at the water levels specified by their manufacturers (Fig. 11). The systems aqua defence, NOAQ boxwall, Mobildeich, Öko-Tec tubewall (Öko-Tec TW), and Tiger Dam with anchoring and skirt (Tiger Dam with A) held a full water head with low incidences of overflow. The systems we could not dam up to maximum capacity (AQUARIWA, INDUTAINER, Flutschutz DCT and Hydrobaffle) were capable of reaching higher water levels than those specified by the manufacturers. The Tiger Dam tube system was only able to achieve the protection height of $0.6 \mathrm{~m}$ specified by the manufacturer by the additional use of an upstream skirt and anchoring to the ground; a test set-up without the skirt and anchoring threatened an early system failure. The Quick Damm Type $\mathrm{M}$ and Aqua Barrier systems were not available in sufficient quantities and could only be tested in combination with the AQUARIWA system. Therefore, water was only dammed up to a height of $0.6 \mathrm{~m}$. Since the tests were carried out without any further loads caused by currents, waves, flotsam, etc., the possibility of increasing the protection heights given by the manufacturers cannot be deduced. Table 2 summarises the advantages and disadvantages of the various system types as determined within the framework of our test set-ups.

The dismantling of the SBRSs tested was generally uncomplicated. In the case of water-filled systems, the number, position and size of the openings for emptying the systems significantly influence the emptying time as well as the possibility of simple complete emptying. Even if only a small amount of residual water remains in the system, the resulting weight can exceed a manageable level. All systems must always be cleaned and dried before being stored for reuse. The INDUTAINER system may be considered a disposable system as cleaning and drying is difficult owing to its intricate design. However, it has a comparatively low purchase price, so the use of the system can be economical even if only used once. Some other SBRSs have limited disposal costs after use. This applies in particular to systems in which the upstream skirt is (preferably) weighted down with sandbags. However, the sandbag requirement, at approximately four sandbags per metre, is low.

Admittedly, these tests were carried out under idealised conditions using a bundle of wooden slats as flotsam. Since the failure of an SBRS threatens the flooding of the hinterland with a correspondingly high damage potential and SBRSs are to be regarded as more susceptible to mechanical impacts and vandalism due to their design, these risks should be evaluated particularly critically. Mechanical impacts and vandalism, however, are also possible when using sandbag systems. In the opinion of the authors, these aspects, despite their particular relevance to SBRSs, should therefore not be an exclusion criterion. Instead, it is advisable to place higher demands on the monitoring of SBRSs during use. 


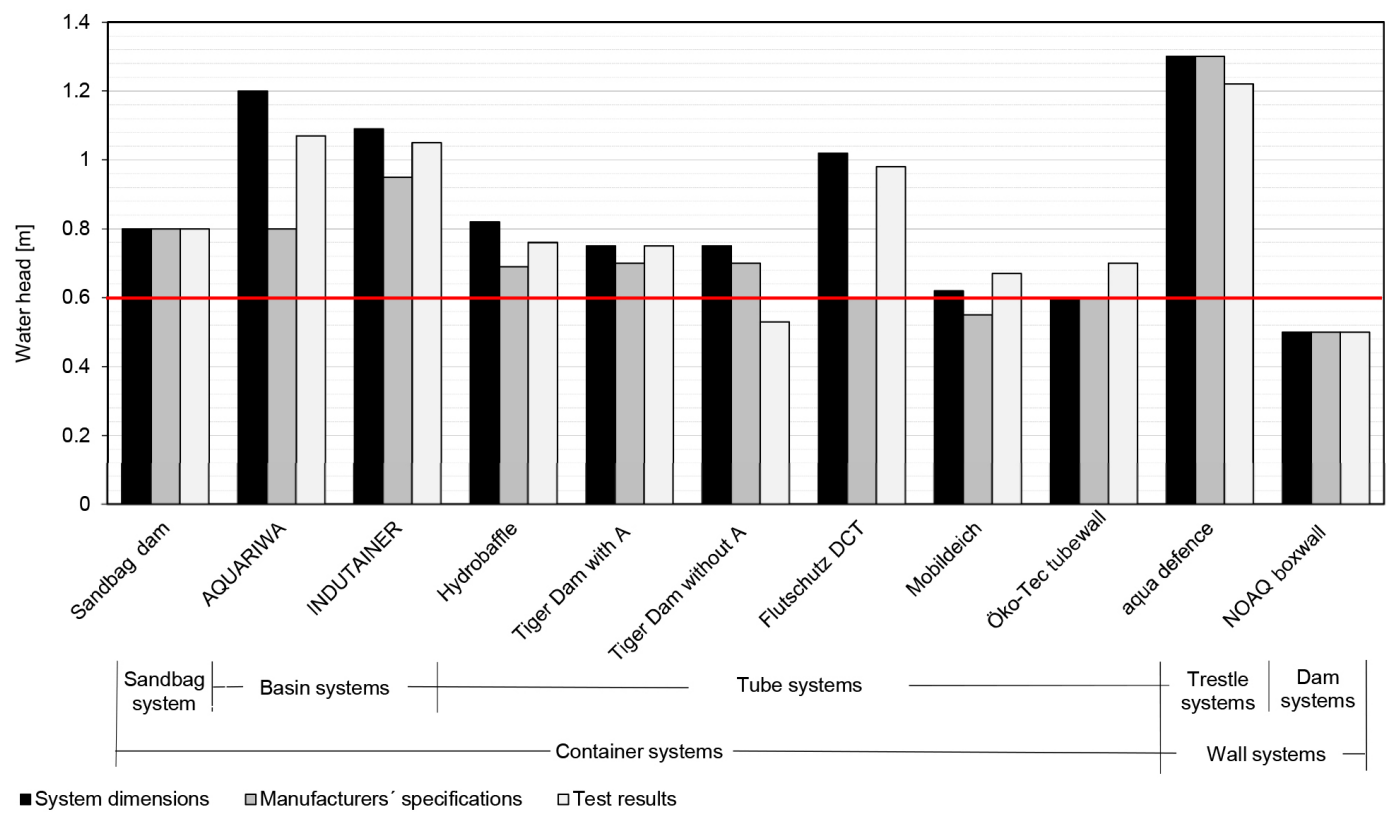

Figure 11. Water levels achieved during the test set-ups (Massolle et al., 2018). The red line marks the maximum water height of $0.6 \mathrm{~m}$, which is recommended for the unscheduled use of SBRSs (BWK, 2005).

The guidelines for loss prevention issued by the German Insurers for Mobile Flood Defence Systems (VdS Schadenverhütung $\mathrm{GmbH}$, 2014) contain a specimen evaluation form for SBRSs, which is intended to serve as a decision-making aid when evaluating systems for use in flood defence. The SBRSs tested were evaluated in accordance with these guidelines; for comparison, the sandbag dam was also evaluated according to these guidelines (Table 3 ). For sandbagging, the evaluation is, where applicable, comparable with the evaluation of the sandbag dam, load drain and temporary ring dam. The evaluation criteria relate to application, stability, procurement, durability, installation, dismantling, maintenance and logistics. If a specification could not be determined or derived from the results of the test set-ups, manufacturers' specifications were used or the evaluation was carried out on the basis of theoretical assessments. The failure mechanisms that are related to the surface an SBRS is installed on, such as those caused by hydraulic heave or erosion, were not considered owing to their dependence on the variable site conditions encountered in operational practice. The systems' connections to walls or the like, the possibility of laying the systems in curves or with angles, and the systems' behaviour on different substrates (such as soft, solid, rough, smooth, even, uneven, permeable and impermeable) were also not considered. The criteria on which the system evaluations are based are described in Table 4.

\section{Deployment costs, time involved, helpers and logistics}

\subsection{Description of scenarios}

The costs as well as the time, helper and logistical requirements for the installation and dismantling of sandbag systems and SBRSs were determined for the following three different cases:

1. temporary flood dam,

2. load drain in the case of a saturated dike over an extensive area and

3. ring dam for reinforcement against heavy punctual exit of seepage on the inner embankment of a dike.

In case 1 , in addition to the sandbag dam, three different SBRS types (basin, tube and trestle) were considered. Regarding the temporary flood dam, based on the experiences of the test performances described in Sect. 2, one manufacturer of each system type was selected. Although there was more than one suitable system for each system type available, the scope of the investigations had to be limited owing to financial and temporal reasons. Regarding their function, i.e. protection against flooding, the chosen systems can be seen as equivalent to sandbagging based on the experience of the test set-ups. Although the systems show different safety margins, the degree of safety can only be defined in detail knowing relevant parameters such as the coefficient of friction, which were outside the scope of the analysis carried out. In cases 2 and 3, the only suitable SBRSs on the market are provided by Flutschutz. The systems' performances on the 
Table 2. Summary of the most important advantages and disadvantages of different system types.

\begin{tabular}{|c|c|}
\hline \multicolumn{2}{|l|}{ Basin system } \\
\hline Advantages & $\begin{array}{l}\text { - High stability even with a low volume of or } \\
\text { no retained water (with the influence of wind or } \\
\text { similar) } \\
\text { - Seals well even with a low volume of retained } \\
\text { water } \\
\text { - Sand filling offers a high level of safety }\end{array}$ \\
\hline Disadvantages & $\begin{array}{l}\text { - Installation time } \\
\text { - Filling material }\end{array}$ \\
\hline \multicolumn{2}{|l|}{ Tube system } \\
\hline Advantages & $\begin{array}{l}\text { - High stability even with a low volume of or } \\
\text { no retained water (with the influence of wind or } \\
\text { similar) } \\
\text { - Seals well even with a low volume of retained } \\
\text { water }\end{array}$ \\
\hline Disadvantages & $\begin{array}{l}\text { - Installation time } \\
\text { - Filling material }\end{array}$ \\
\hline \multicolumn{2}{|c|}{ Flap, trestle and dam systems } \\
\hline Advantages & $\begin{array}{l}\text { - Installation time } \\
\text { - No filling material } \\
\text { - Usually allows for overflow }\end{array}$ \\
\hline Disadvantages & $\begin{array}{l}\text { - Good stability only with an increasing height } \\
\text { of retained water (problematic with wind influ- } \\
\text { ence or similar) } \\
\text { - Good seal only with higher levels of retained } \\
\text { water }\end{array}$ \\
\hline
\end{tabular}

dry dike were in accordance with the manufacturer's statements. Furthermore, the mode of action of the corresponding SBRSs is the same as for sandbagging. The authors therefore assume the SBRS Flutschutz load drain and Flutschutz ring dam equivalent to sandbagging, not taking into account possible differences in safety margins. When determining the costs of the installation and dismantling of the systems the costs of logistics (hiring the truck and driver and paying for fuel and repair) and helpers were taken into account as well as the costs of materials (sand, sandbags and acquisition cost of SBRSs, including component parts) and the disposal of sand and sandbags.

In the case of the temporary flood dam, a protection length of $100 \mathrm{~m}$ and a protection height of $1.0 \mathrm{~m}$ were assumed. The height of the sandbag dam was assumed to be $1.0 \mathrm{~m}$ as the dam can theoretically protect against water levels up to its full height. The SBRS AQUARIWA (basin system) with a protection height of $1.0 \mathrm{~m}$ and a freeboard of $0.5 \mathrm{~m}$, the Flutschutz DCT system with a protection height of $0.6 \mathrm{~m}$ and a freeboard of $0.3 \mathrm{~m}$, and the aqua defence product (trestle system) with a maximum protection height of $1.3 \mathrm{~m}$ (identical to system height) were compared. The differences in the protection heights are system specific and cannot therefore be avoided. The practical tests (cf. Massolle et al., 2018) have shown that the Flutschutz DCT can dam a water head up to a height of $1.0 \mathrm{~m}$; due to the lateral pressure exerted when filling the test basin, performance can be increased above the system height of $0.9 \mathrm{~m}$ as specified by the manufacturer. In case 2, one Flutschutz load drain was compared with the equivalent length of a sandbag load drain, and, in case 3, one Flutschutz ring dam was compared with one sandbag ring dam (see Fig. 3).

All cost calculations assumed technical assistance would be provided by the disaster services of the German Federal Agency for Technical Relief (THW). Such federal assistance takes place within the framework of inter-agency cooperation and is generally requested by the responsible state authorities during extreme flood events in Germany. For the resources made available - primarily vehicles, pumps and hoses as well as THW helpers - the costs were calculated on the basis of the Ordinance on the Implementation and Invoicing of Assistance provided by the THW (Verordnung über die Durchführung und Abrechnung von Hilfeleistungen des Technischen Hilfswerks), in accordance with the Annex to Sect. 4 (3) of the THW Invoicing Ordinance (Bundesministerium der Justiz und für Verbraucherschutz, 2019). During a flood, the Bundeswehr and other relief organisations such as fire brigades and the police can be deployed in addition to the THW. Depending on the organisation, the individual costs may vary; however, this has not been taken into consideration for the present cost estimate.

The distance between the filling station for sandbagging or the storage site of the SBRSs and the site of operation is $5 \mathrm{~km}$, i.e. $10 \mathrm{~km}$ for one round trip. Optimum access to the site of operation allows for the use of trucks. Due to the heavily soaked subsoil in cases 2 and 3, the access from the dike defence road to the dike toe is limited; therefore, additional helpers are needed to form a sandbag chain and pass on the sandbags to the dike. The comparable SBRSs in cases 2 and 3 can be carried to the dike by two people. The operation is carried out with THW personnel and means. The THW provide trucks, as well as pumps and hoses, for the water-filled SBRSs. Furthermore, it is assumed that the travel distances for the installation and dismantling of the systems are the same length. That is why the logistics of installation and dismantling show no differences.

The requirement for sandbags and sand, as well as the labour needed for filling and laying the sandbags, is based on empirical values supplied by the THW (THW, 2017). The labour time needed for the installation of the SBRSs was estimated on the basis of the authors' empirical values (cf. Massolle et al., 2018). In the case of water-filled systems in particular, the time required to dismantle an SBRS is less than that required for the installation as the system components can be allowed to drain at the same time without the need for pumps. For the water-filled systems, therefore, the time required for dismantling was estimated to be $20 \%$ of the time 


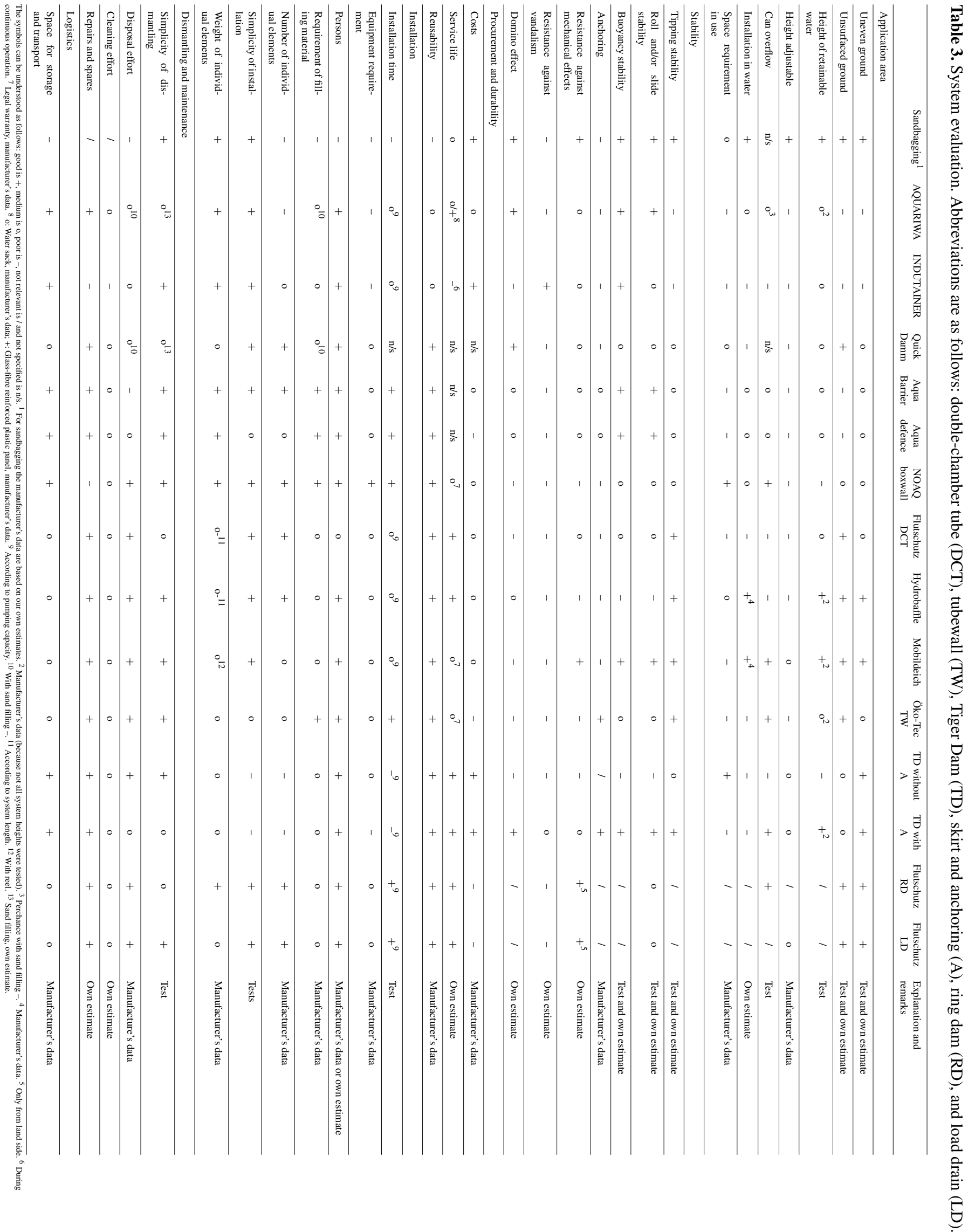


Table 4. Evaluation criteria.

\begin{tabular}{|c|c|}
\hline Area of application & Evaluation criteria \\
\hline Uneven ground & Applicable on unevenness, curbstones, etc. \\
\hline Unsurfaced ground & Special requirements for the condition of the foundation surface \\
\hline Height of retainable water & $\begin{array}{l}\text { Height of retainable water up to } 0.6 \mathrm{~m} \text { is }- \text {, up to } 1.5 \mathrm{~m} \text { is o and up to } 3.0 \mathrm{~m} \text { is }+ \\
\text { Recommendations for unscheduled use of SBRSs according to BWK are observed (2005) }\end{array}$ \\
\hline Height adjustable & Subsequent increase possible \\
\hline Can overflow & $\begin{array}{l}\text { Overflow capability according to manufacturer }(\mathrm{M}) \text { or determined in authors' tests (AT) } \\
\text { No is -, yes (AT or M) is o, and yes (AT and } \mathrm{M}) \text { is + }\end{array}$ \\
\hline Installation in water & Manufacturer's specification or own estimate based on system characteristics \\
\hline Space requirement in use & $\begin{array}{l}\text { Depth including any upstream skirt } \\
\leq 1.0 \mathrm{~m} \text { is }+, \leq 2.0 \mathrm{~m} \text { is } \mathrm{o} \text {, and }>2.0 \mathrm{~m} \text { is }- \text { (refers to the system variants tested) }\end{array}$ \\
\hline \multicolumn{2}{|l|}{ Stability } \\
\hline Tipping stability & $\begin{array}{l}\text { Tube systems are less prone to tipping than dam or trestle systems. The heavier the installed systems, } \\
\text { the less prone they are to tipping. Sinking, including selective sinking, into the ground increases the risk } \\
\text { of tipping. Anchoring or securing against buoyancy counteracts tipping. }\end{array}$ \\
\hline Roll and/or slide stability & $\begin{array}{l}\text { Tube systems are generally more susceptible to rolling away. The lower the weight and the smoother the } \\
\text { foundation surface of the system, the easier it is for the system to slip. Anchoring or securing against } \\
\text { buoyancy counteracts sliding or rolling. The Flutschutz load drain and ring dike always have to be } \\
\text { positioned partly on the horizontal plane in front of the land-side dike embankment. }\end{array}$ \\
\hline Buoyancy stability & $\begin{array}{l}\text { The risk of system failure due to buoyancy is greater for filled systems with a lower weight. Depending } \\
\text { on the shape, buoyancy forces can also act on the water side (e.g. in tube systems). Systems with a large } \\
\text { foundation surface which achieve their load-bearing effect through the vertical water pressure from } \\
\text { the outside also have a greater risk of failure due to buoyancy. An upstream skirt, drainage, a seal or } \\
\text { anchoring counteracts failure caused by buoyancy. }\end{array}$ \\
\hline Anchoring & System can be anchored against wind, current, slipping or rolling \\
\hline Resistance to mechanical effects & Susceptibility to damage, e.g. by flotsam impact \\
\hline Resistance against vandalism. & Susceptibility to deliberate damage \\
\hline Domino effect & Threat to the entire dam due to failure of individual elements \\
\hline \multicolumn{2}{|l|}{ Procurement and durability } \\
\hline Costs & $\begin{array}{l}\text { EUR } \leq 100 \text { per metre is }+, \text { EUR } \leq 300 \text { per metre is o, EUR }>300 \text { per metre is }- \\
\text { Refers to the system variants tested }\end{array}$ \\
\hline Service life & $\begin{array}{l}\text { Service life according to the manufacturer } \\
\leq 1 \text { year is }-, \leq 5 \text { years is } 0,>5 \text { years is }+\end{array}$ \\
\hline Reusability & Manufacturer's data \\
\hline \multicolumn{2}{|l|}{ Installation } \\
\hline Installation time & $\begin{array}{l}\text { Installation time according to manufacturer or from own test. For all water-filled systems, the installa- } \\
\text { tion time depends on the pump used. }\end{array}$ \\
\hline Equipment requirement & $\begin{array}{l}\text { Tarpaulins, sandbags, hoses, pumps, adapters or blowers } \\
\text { tarpaulin and others is }- \text {, tarpaulin or others is o, no equipment requirement is }+\end{array}$ \\
\hline People & $\leq 2$ people is + \\
\hline Requirement of filling material & Sand filling is - , water filling is $o$, no filling is + \\
\hline Number of individual elements & Number of individual parts \\
\hline Simplicity of installation & System installation easy to understand and to perform \\
\hline Weight of individual elements & $\begin{array}{l}\leq 35 \mathrm{~kg} \text { is }+, \leq 100 \mathrm{~kg} \text { is } \mathrm{o},>100 \mathrm{~kg} \text { is }- \\
\text { Refers to the system variants tested }\end{array}$ \\
\hline
\end{tabular}


Table 4. Continued.

\begin{tabular}{ll}
\hline Area of application & Evaluation criteria \\
\hline Dismantling and maintenance & \\
\hline Simplicity of dismantling & System dismantling easy to understand and easy to perform \\
\hline Disposal costs & Disposal of foils, tarpaulins and sandbags or general disposal after use \\
\hline Cleaning costs & Effort involved in system cleaning \\
\hline Repairs and spares & Minor damage can be repaired by the user. Material and spare parts are available. \\
\hline Logistics & \\
\hline Space for storage and transport & Compactness of the dismantled system \\
\hline
\end{tabular}

required for installation. In practice, it should be noted that these estimates depend on the conditions and accessibility on site and, moreover, at least in Germany, dismantling is generally not financed by the federal authorities and therefore not by the THW. With the end of the flood hazard, and thus the disaster event, assistance on the part of the federal authorities is terminated; the municipalities and administrative districts become responsible for the measures taken. Due to a lack of helpers, this can often lead to considerable problems following major flood events.

The following times were assumed for cleaning the systems:

- Flutschutz DCT, length $10 \mathrm{~m}-1.5 \mathrm{~h}$,

- aqua defence, length $1.22 \mathrm{~m}-5 \mathrm{~min}$,

- AQUARIWA, length $1.5 \mathrm{~m}$ - $5 \mathrm{~min}$,

- Flutschutz load drain - $1 \mathrm{~h}$, and

- Flutschutz ring dam - $1 \mathrm{~h}$.

The sandbag requirement for SBRSs with upstream skirt (AQUARIWA and aqua defence) is four sandbags per linear metre. The basic helper requirement is 10 people for sandbagging and 2.5 people per SBRS, taking supervisors (lower command such as group leaders) into account. In the case of SBRSs, group leaders can take care of two different areas of application simultaneously; therefore, only half a helper is counted for the lower command of the installation of an SBRS per $100 \mathrm{~m}$. The other two helpers install the SBRS, resulting in 2.5 people per SBRS in total. In practice, the systems should be set up by a larger team of helpers, but fictitious helper teams with a minimum number of helpers were assumed for the calculation. The estimated remuneration to be reimbursed is estimated to be EUR 22.00 per helper hour (Bundesministerium der Justiz und für Verbraucherschutz, 2019). The average weight of a sandbag is $12 \mathrm{~kg}$ (THW, 2017). A requirement of $15 \mathrm{~kg}$ sand per sandbag was assumed in order to take overfilling and sand losses into account. On the other hand, no reserve margin for defective sandbags is taken into account but is considered to be included in the excess demand for sand. A sandbag purchase price of EUR 0.20 takes into account the slight price increase to be expected during a flood event; sand is calculated at a price of EUR 10.5 per tonne. Travel costs were assumed to be EUR 1.52 per litre diesel and $25 \mathrm{~L}$ per $100 \mathrm{~km}$. No voluntary or private-sector assistance is taken into account. However, the participation of other volunteers, for example local people, can significantly reduce the costs of the construction of a sandbag dam as the helper costs make up the largest cost factor. It should be taken into account, though, that in the case of volunteers from the local population, the resulting costs are usually borne by the volunteers themselves; the costs are therefore only transferred. The calculation also does not include costs of (1) travel, food, accommodation or the sanitary needs of the helpers; (2) upper command; (3) long transport routes and alternative means of transport in cases of poor access; (4) other material requirements (such as shovels for filling the sandbags); (5) the transport of sand and supplementary materials; (6) the storage of SBRSs, sandbags and shovels, etc.; and (7) necessary repairs to SBRSs.

In principle, the selected SBRSs are reusable. Only the AQUARIWA system needs to have the inner bags replaced after using the system; the price per bag is low and was therefore neglected in the calculation. However, to replace worn-off elements, $5 \%$ of the investment costs are estimated. It is assumed that with smaller quantities of SBRSs, storage on site, e.g. by local dike management units (Deichverbaende), is possible without difficulty. Only in the case of larger stocks are higher demands placed on storage capacities. Just like SBRSs, sandbags must be stored, but they have a significantly shorter shelf life than SBRSs (see Sect. 2). In view of this, the calculation equates the repair requirements of SBRSs with the inspection and renewal requirements of stored sandbags.

The need to regularly test the construction of SBRSs is likewise equated with the requirement to carry out flood protection exercises when relying on the use of sandbag systems. It was also assumed that the sandbag systems, like the SBRSs, should be continuously monitored during a flood event in order to monitor their functionality and to check the systems for damage caused by mechanical influences or 
vandalism. If deemed appropriate, the SBRSs should be inspected at shorter intervals than sandbag systems. However, the additional requirement for labour to carry out inspections is comparatively low and was therefore neglected.

\subsection{Costs of deployment}

The overview of the total cost of installing and dismantling the flood protection systems shows that, under the assumed conditions, the costs resulting from the one-off use of the SBRSs are around 30\%-50\% higher than for sandbagging. However, since the SBRSs, in contrast to sandbags, are largely reusable, the higher investment costs of the SBRSs are already offset during their second application. Table 5 shows the cost estimates for the temporary flood dams (case 1), and Table 6 shows the cost estimates for the load drain (case 2) and the ring dam (case 3). In each case, the costs incurred for installing the systems exceed the costs of their dismantling. Whereas the costs of dismantling the sandbag dam amount to approximately $70 \%$ of the costs of installation, the dismantling costs of SBRSs are in the low singledigit percentage range when compared with their respective installation costs.

In the case of sandbagging, both sand and sandbags must first be procured. These are usually only stocked in limited quantities, and in the event of procurement during a flood event it must be expected that prices will rise sharply, even exceeding the cost of sandbags assumed here. The sandbags must then be filled and laid with a great deal of time and effort. These aspects must be weighed against the high initial investment costs of the SBRSs, which, however, can be used several times. In order to replace damaged systems after use, an average new procurement requirement of $5 \%$ of the initial investment cost is assumed within the system service life. The number of sandbags required to weigh down and seal the upstream skirt of an SBRS are comparatively insignificant. The logistical costs of installation and dismantling are quite similar for sandbags and SBRSs due to the equal travel distances assumed; for sandbagging they are slightly higher compared to SBRSs, owing to the greater bulk of sandbagging systems. Basically, the logistical costs of all the systems are comparatively low, which is also due to the comparatively low costs of the use of THW vehicles assumed here. When dismantling, the costs of sandbagging are higher than of the SBRSs, owing to the extra need for helpers and the disposal of sandbags. However, if it is possible to deploy heavy equipment for the dismantling of a sandbag dam, these costs can be lower than those estimated in the present calculation because of the lower requirement for helpers and the shorter time involved. Overall, the largest cost items for sandbagging are the costs of the deployment of helpers, the procurement of materials (sand and sandbags), and, for the SBRSs, the procurement of the systems. If, in addition to the costs of installation, the costs of dismantling are also taken into account, the purchase of SBRSs makes sense from a financial point of view as the additional costs compared with sandbagging are already offset during the second deployment. The investment costs did not include a quantity discount for the purchase of longer system lengths.

From a financial point of view, the use of SBRSs as a temporary flood dam is particularly worthwhile for protection against higher flood levels. If the protective height is reduced, the installation costs of the temporary sandbag dam decrease owing to the lower sandbag requirement. SBRSs, on the other hand, can rarely be flexibly adjusted in height, so, with lower system heights, the offsetting of costs in comparison to sandbag dams of low height only takes place after a number of deployments. For example, the costs of constructing a sandbag dam with a height of $0.50 \mathrm{~m}$ and a length of $100 \mathrm{~m}$ are only approximately EUR 8090 for installation and approximately EUR 5352 for dismantling, giving a total of approximately EUR 13442 for installation and dismantling. If an SBRS is offered in different system heights, savings can also be expected if lower system heights are used, but these are less significant. It should also be noted that the procurement costs of SBRSs supplied by other manufacturers may differ from those of the manufacturers considered here.

If there is insufficient water available from natural sources (e.g. river water) in the immediate vicinity of where waterfilled systems are to be installed, the costs of the water filling of hydrants are comparatively low (approx. EUR 400 Flutschutz DCT and EUR 150 AQUARIWA). If tank trucks have to be used, however, the logistical effort increases. Notwithstanding, the time, material and helper advantages of SBRSs remain in all of the cases considered here.

The calculations did not take into account the costs of upper command or of travel, meals, overnight accommodation and sanitary requirements of the helpers. For upper command, i.e. the disaster control management, technical incident command and platoon, EUR 5 per helper in the lower command and day can be assumed. The costs of upper command are realistic overhead costs related to the number of helpers in action. With an estimate of EUR 25 per day to cover the overnight accommodation, food and sanitary needs of the helpers and with a helper day of $12 \mathrm{~h}$, in cases 1,2 and 3 , approximately $6 \%$ and $1 \%$ more costs are incurred per sandbag system and SBRS respectively.

\subsection{Time, helper and logistics requirements}

For cases 1, 2 and 3, the estimated time, helper and logistics requirements are shown in Tables 7 and 8 . Time materials refers to the time needed to fill the sandbags; aqua defence and AQUARIWA SBRSs need sandbags in order to weight down the upstream skirt. Time logistics covers the time for loading and unloading the trucks as well as the time for the outward and return journey between the filling station or storage site and the site of operation, which is calculated as $1 \mathrm{~h}$ per truck. It is assumed that there is an unrestricted number of trucks available, which is of course only theoretical, result- 
Table 5. Comparison of the costs of the installation and dismantling of sandbag systems and SBRSs - temporary flood dam, protection length $100 \mathrm{~m}$ (case 1).

\begin{tabular}{|c|c|c|c|c|}
\hline & Sandbag dam & Flutschutz DCT & Aqua defence & AQUARIWA \\
\hline Helpers, incl. lower command & 10 & 2.5 & 2.5 & 2.5 \\
\hline Sandbag requirement $(40 \times 60 \mathrm{~cm}$, empty $)$ & 16500 & - & 400 & 400 \\
\hline \multicolumn{5}{|l|}{ Installation } \\
\hline Time per dam (h) & 61.88 & 7.50 & 8.48 & 10.71 \\
\hline Costs of helpers (EUR) & 13612.50 & 412.50 & 466.40 & 589.05 \\
\hline Costs of materials, incl. replacements (EUR) & 5898.75 & 42930.33 & 47400.15 & 51758.87 \\
\hline Costs of trucks, incl. fuel (EUR) & 641.47 & 35.06 & 37.56 & 28.02 \\
\hline Total installation costs without materials (EUR) & 14253.97 & 447.56 & 503.96 & 617.07 \\
\hline $\begin{array}{l}3 \% \text { sundry costs (EUR), based on total } \\
\text { operating costs of EUR } 15-150\end{array}$ & 150.00 & 15.00 & 15.12 & 18.51 \\
\hline Total costs of installation (EUR) & 20302.72 & 43392.89 & 47919.23 & 52416.95 \\
\hline \multicolumn{5}{|l|}{ Dismantling } \\
\hline Time per dam (h) & 20.63 & 16.55 & 12.96 & 9.10 \\
\hline Costs of helpers (EUR) & 4537.50 & 907.50 & 712.80 & 390.61 \\
\hline Costs of materials (EUR) & 8250.00 & - & 200.00 & 200.00 \\
\hline Costs of trucks, incl. fuel (EUR) & 641.47 & 35.06 & 37.56 & 28.02 \\
\hline Total dismantling costs without materials (EUR) & 5178.97 & 942.56 & 750.36 & 418.63 \\
\hline $\begin{array}{l}3 \% \text { sundry costs (EUR) based on } \\
\text { total operating costs of EUR } 15-150\end{array}$ & 150.00 & 28.28 & 22.51 & 15.00 \\
\hline Total costs of dismantling (EUR) & 13578.97 & 970.83 & 972.87 & 633.63 \\
\hline \multicolumn{5}{|l|}{ Installation and dismantling totals } \\
\hline Total costs (EUR) & 33881.69 & 44363.72 & 48892.10 & 53050.58 \\
\hline
\end{tabular}

ing in an overall time for logistics of $1 \mathrm{~h}$. In reality, the overall time would increase depending on the actual available number of trucks. Time installation refers to the installation of the specific system, including if necessary additional time for a sandbag chain. Time dismantling refers to the dismantling of the individual systems as well as to time spent cleaning the SBRSs if necessary, and also including additional time for a sandbag chain. Time taken for the disposal or storage of SBRSs was not taken into account.

The advantages of the SBRSs in terms of time, materials and helpers are clearly visible. In case 1 , the use of SBRSs requires approximately $25 \%-30 \%$ of the time, approximately $5 \%-7 \%$ of the helper hours and approximately $5 \%$ of the trucks compared to the sandbag dam. If more helpers or trucks are used, the respective proportions shift, but the total effort remains the same. In case 2 and case 3, approximately $40 \%$ of the time and approximately $6 \%$ of the helper hours are required when using SBRSs as opposed to sandbagging systems. The logistics data in case 2 and case 3 were calculated assuming fully loaded trucks. Eight Flutschutz load drains or Flutschutz ring dams can be transported per truck, so when using these SBRSs there is a need for only approximately $8 \%-9 \%$ of the trucks required for sandbagging.

When sandbagging is used, poor access, and thus the need for sandbags to be passed over longer distances by means of a sandbag chain (see Fig. 2), may result in a significantly increased need for helpers or in the use of alternative means of transport, such as helicopters or boats, which can only transport sandbags in small numbers. This can also considerably increase the time required for transport as well as the costs incurred. The possible scenarios are manifold and could therefore not be considered in detail. SBRSs do not need additional helpers in cases of poor accessibility, because, due to their relatively low weight, the required number can be put in place much more easily, e.g. by the use of special vehicles which can access wet ground but cannot carry a lot of weight.

\section{Conclusion}

Tests of various SBRSs with a focus on stability, functionality and handling were carried out. The experiences from the test set-ups show that SBRSs, owing to their functionality, their labour- and time-saving characteristics, and their lower requirement for materials, have the potential to make operational flood defence more efficient than with the use of sandbags alone. Since SBRSs are technical systems whose functional capability must be proven before they can be used, the introduction of a test and certification system is urgently 
Table 6. Comparison of the costs of the installation and dismantling of sandbag systems and SBRSs - load drain (case 2) and ring dam (case 3).

\begin{tabular}{|c|c|c|c|c|}
\hline & \multicolumn{2}{|c|}{ Load drain } & \multicolumn{2}{|c|}{ Ring dam } \\
\hline & Sandbag & Flutschutz & Sandbag & Flutschutz \\
\hline Helpers, incl. lower command & 10 & 2.5 & 10 & 2.5 \\
\hline Sandbag requirement $(40 \times 60 \mathrm{~cm}$, empty) & 980 & - & 900 & - \\
\hline \multicolumn{5}{|l|}{ Installation } \\
\hline Time per element $(\mathrm{h})$ & 4.90 & 0.50 & 4.50 & 0.50 \\
\hline Costs of helpers (EUR) & 1078.00 & 27.50 & 990.00 & 27.50 \\
\hline Costs of materials, incl. replacements (EUR) & 350.53 & 3068.78 & 321.75 & 3748.51 \\
\hline Costs of trucks, incl. fuel (EUR) & 41.31 & 6.93 & 38.18 & 6.93 \\
\hline Total costs without materials (EUR) & 1119.31 & 34.43 & 1028.18 & 34.34 \\
\hline $\begin{array}{l}3 \% \text { sundry costs (EUR) based on } \\
\text { total operating costs of EUR } 15-150\end{array}$ & 33.58 & 15.00 & 30.85 & 15.00 \\
\hline Total costs of installation (EUR) & 1503.24 & 3118.21 & 1380.78 & 3797.93 \\
\hline \multicolumn{5}{|l|}{ Dismantling } \\
\hline Time per dam (h) & 2.45 & 1.10 & 2.25 & 1.10 \\
\hline Costs of helpers (EUR) & 539.00 & 60.50 & 495.00 & 60.50 \\
\hline Costs of materials (EUR) & 490.00 & - & 450.00 & - \\
\hline Costs of trucks, incl. fuel (EUR) & 41.31 & 6.93 & 38.18 & 6.93 \\
\hline Total operating costs without materials (EUR) & 580.31 & 67.43 & 533.18 & 67.43 \\
\hline $\begin{array}{l}3 \% \text { sundry costs (EUR) based on } \\
\text { total operating costs of EUR } 15-150\end{array}$ & 17.41 & 15.00 & 16.00 & 15.00 \\
\hline Total costs of dismantling (EUR) & 1087.72 & 82.43 & 999.18 & 82.43 \\
\hline \multicolumn{5}{|l|}{ Installation and dismantling totals } \\
\hline Total costs (EUR) & 2590.96 & 3200.63 & 2379.96 & 3880.36 \\
\hline
\end{tabular}

Table 7. Comparison of time, helpers and logistics requirements for the installation and dismantling of sandbag systems and SBRSs temporary flood dam (case 1).

\begin{tabular}{|c|c|c|c|c|}
\hline & Sandbag dam & FlutschutzDCT & Aqua defence & AQUARIWA \\
\hline Helpers, incl. lower command & 10 & 2.5 & 2.5 & 2.5 \\
\hline Trucks & 26 & 2 & 2 & 1 \\
\hline \multicolumn{5}{|l|}{ Installation } \\
\hline Time materials (h) & 41.25 & - & 2.00 & 2.00 \\
\hline Time logistics (h) & 1.00 & 1.00 & 1.00 & 1.00 \\
\hline Time installation (h) & 20.63 & 7.50 & 6.48 & 8.71 \\
\hline Total time, incl. logistics (h) & 62.88 & 8.50 & 9.48 & 11.71 \\
\hline Total helper hours (h) & 618.75 & 18.75 & 21.20 & 26.78 \\
\hline \multicolumn{5}{|l|}{ Dismantling } \\
\hline Time materials (h) & - & - & - & - \\
\hline Time logistics (h) & 1.00 & 1.00 & 1.00 & 1.00 \\
\hline Time dismantling, incl. cleaning the SBRS (h) & 20.63 & 16.50 & 12.96 & 7.10 \\
\hline Total time, incl. logistics $(\mathrm{h})$ & 21.63 & 17.50 & 13.96 & 8.10 \\
\hline Total helper hours (h) & 206.25 & 41.25 & 32.40 & 17.76 \\
\hline \multicolumn{5}{|l|}{ Installation and dismantling totals } \\
\hline Total time, incl. logistics $(\mathrm{h})$ & 84.50 & 26.00 & 23.44 & 19.81 \\
\hline Total helper hours (h) & 825.00 & 60.00 & 53.60 & 44.53 \\
\hline
\end{tabular}


Table 8. Comparison of time, helpers and logistics requirements for the installation and dismantling of sandbag systems and SBRSs - load drain (case 2) and ring dam (case 3).

\begin{tabular}{lrr|rr} 
& Load drain & \multicolumn{2}{r}{ Ring dam } \\
\cline { 2 - 5 } & Sandbag & Flutschutz & Sandbag & Flutschutz \\
\hline Helpers, incl. lower command & 10 & 2.5 & 10 & 2.5 \\
Trucks & 2 & 1 & 2 & 1 \\
\hline Installation & & & & \\
\hline Time materials (h) & 2.45 & - & 2.25 & - \\
Time logistics (h) & 1.00 & 1.00 & 1.00 & 1.00 \\
Time installation (h) & 2.45 & 0.50 & 2.25 & 0.50 \\
Total time, incl. logistics (h) & 5.90 & 1.50 & 5.50 & 1.50 \\
Total helper hours (h) & 49.00 & 1.25 & 45.00 & 1.25 \\
\hline Dismantling & & & & \\
\hline Time materials (h) & - & - & - & - \\
Time logistics (h) & 1.00 & 1.00 & 1.00 & 1.00 \\
Time dismantling, incl. cleaning the SBRS (h) & 2.45 & 1.10 & 2.25 & 1.10 \\
Total time incl. logistics (h) & 3.45 & 2.10 & 3.25 & 2.10 \\
Total helper hours (h) & 24.50 & 2.75 & 22.50 & 2.75 \\
\hline Installation and dismantling totals & & & & \\
\hline Total time, incl. logistics (h) & & & \\
Total helper hours (h) & 73.50 & 4.00 & 67.50 & 4.00 \\
\hline
\end{tabular}

recommended. A basis for the development of a certification system according to German standards is already available in the BWK leaflet Mobile Flood Protection Systems (BWK, 2005) and the international certification systems of FM Approvals (FM Approvals, 2019) and BSI Kitemark (2019a), as well as in the test results described here and in Massolle et al. (2018).

Further aspects have to be considered when using SBRSs instead of sandbagging. These include the lower flexibility of SBRSs to be adaptively applied in emergency situations, higher demands on trained personnel, the creation of hazards by assembly errors, defects in their construction, mechanical influences due to flotsam, vehicles and people, vandalism, the possibility of collective failure (domino effect), and the influences of currents, winds and waves. The hazards introduced through the use of SBRSs cannot entirely be ruled out; but the hazards can be minimised by taking appropriate precautions, e.g. installing safety zones adjacent to the systems, anchoring systems to the ground, and tightly monitoring SBRSs and water-side environments. SBRSs also easily allow for the impounding of higher floodwater levels, which is on the one hand an advantage but on the other hand results in the greater probability of subsoil failure if high water levels are impounded. In general, the use of SBRSs can lead to higher demands on subsoils. Many of the aspects mentioned can be laid down in guidelines to support decision makers with regard to the possible use of SBRSs. However, taking into account possible catastrophic consequences in the event of failure, the installation of SBRSs should be planned and executed under the supervision of specialists and under special observation during the flood event. From the authors' point of view, SBRSs are a suitable supplement to rather than a full replacement of sandbagging. Especially because of their easy, flexible handling and their reliable usability within a wide range of scenarios, sandbags are an essential means in operational flood defence. No matter whether SBRSs find increasing applications in the future, sandbags will continue to play an important role in flood defence owing to their simple application and high flexibility even if, for example, they are only used to close gaps for which prefabricated systems of a certain length are not suitable.

The authors' determination of the operational costs was carried out for specific scenarios and with several simplifications but nevertheless allows for an approximate estimate of the operational costs of sandbagging and SBRSs under realistic conditions. When used once, all SBRSs show higher overall costs, including costs of investment, logistics, installation and dismantling. The higher total costs result from the higher acquisition costs of the SBRSs investigated. SBRSs are reusable; therefore, with regard to offsetting the higher acquisition costs of SBRSs, the number of times a system can be used within its service life plays a decisive role since the acquisition costs of the systems are offset during their subsequent reuse. Because SBRSs can be transported with comparatively low logistical effort, a more centralised storage system is conceivable, whereby, in the event of flood- 
ing, the systems can be transported from more distant regions that are not immediately affected by the flood to where there is a current need. This would be in the interest of a crossmunicipal and therefore cost-effective acquisition.

All SBRSs investigated show clear time-, material- and personnel-saving advantages. All of these aspects, in particular the time-saving advantage, which could be crucial in quickly providing protection, should be taken into account. The time-, material- and personnel-saving characteristics of SBRSs might offer the possibility to use SBRSs during heavy-precipitation events and flood events with only shortnotice early warning times. Such events can entail high flow velocities, resulting in high potential dynamic loads. Further investigations and a special testing routine would be necessary in order to make reliable statements about the functionality of an SBRS during such events.

From a technical point of view, decision makers are confronted with questions about the reliability of SBRSs, which in general show good functionality comparable to sandbagging and, in terms of time, personnel and material need, better results than sandbagging alone. The question of the functionality of SBRSs can be addressed by introducing independent test routines and certifications. From an economic point of view, decision makers are confronted with the challenge of higher investment costs if SBRSs are purchased. The investigations carried out here indicate that this is not connected to economic losses only if SBRSs are subsequently reused. In addition to the economic aspects, however, it should also be noted that SBRSs can be set up in a significantly shorter period of time, which can often be the basis for effective protection.

Data availability. Relevant underlying data can be requested by mail from the authors. 


\section{Appendix A}

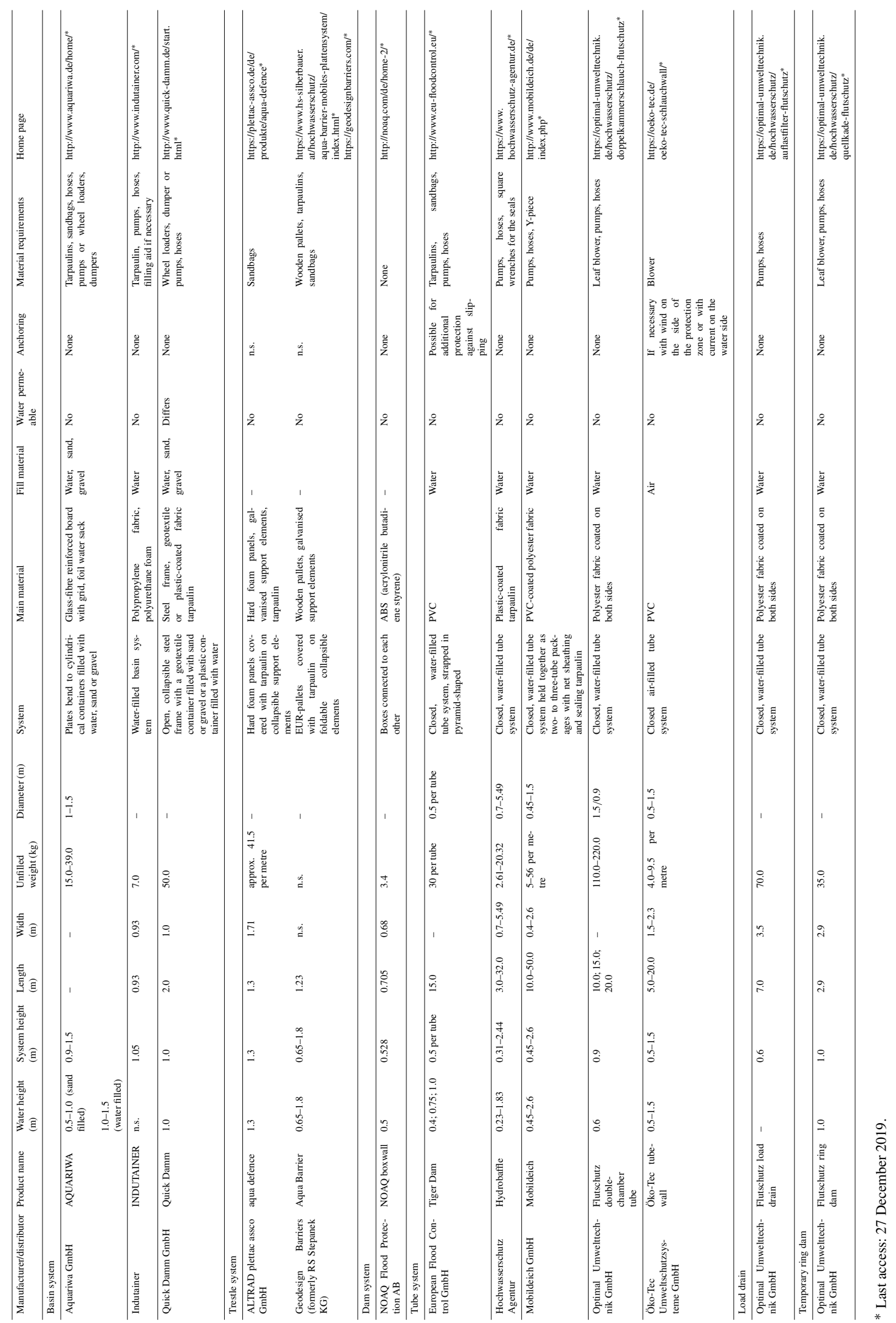


Author contributions. BK conceptualised the study; LL and CM developed the methodology; CM and LL procured the resources; and LL, CM and VK conducted formal analysis. LL prepared the original draft of this manuscript; $\mathrm{BK}, \mathrm{CM}$ and LL reviewed and edited it; and LL and VK created the visualisations. BK and LL supervised the project and BK administered the project and acquired funding.

Competing interests. The authors declare that they have no conflict of interest.

Acknowledgements. The test set-ups were carried out within the framework of the project, Adaptation of flood protection training and dike defence of the THW Training Centre Hoya to the challenges of climate change' (HWS-Bildung, duration 2016-2018), funded within the framework of the German Strategy for Adaptation to Climate Change by the Federal Ministry for the Environment, Nature Conservation and Nuclear Safety and by the THW Foundation. We would like to thank the manufacturers and their distributors for making their systems available for the tests and our student assistants for their active support during the test set-ups. We would furthermore like to thank the anonymous referees for their helpful comments and suggestions.

Financial support. This research has been supported by the Bundesministerium für Umwelt, Naturschutz und nukleare Sicherheit (grant no. 03DAS080) and the THW Foundation.

Review statement. This paper was edited by Heidi Kreibich and reviewed by two anonymous referees.

\section{References}

American National Standards Institute (ANSI) and FM Approvals: American National Standard for Flood Abatement Equipment, ANSI/FM Approvals 2510, FM Approvals, Norwood, 2014.

AQUARIWA: Mobiler Hochwasserschutz in Gartow im Juni 2013, available at: http://www.aquariwa.de/ die-einsaetze/aquariwa-in-gartow-juni-2013/\#die-einsaetze/ aquariwa-in-gartow-juni-2013/, last access: 25 September 2019.

Biggar, K. and Masala, S.: Alternatives to sandbags for temporary flood protection, Alberta Transportation and Utilities Disaster Services Branch and Emergency Preparedness Canada, Edmonton, AB and Ottawa, ON, Canada, 1998.

British Standards Institution (BSI): PAS 1188-2:2014 Flood protection products - Specification, Part 2: Temporary products, Third Edition, The British Standards Institution Group Headquarters, London, 2014.

British Standards Institution (BSI): British Standards Institution Homepage, available at: https://www.bsigroup.com/en-GB/, last access: 25 September 2019a.
British Standards Institution (BSI): Product directory search, available at: https://www.bsigroup.com/en-GB/Product-Directory/, last access: 25 September 2019b.

Bund der Ingenieure für Wasserwirtschaft, Abfallwirtschaft und Kulturbau (BWK) e.V.: Merkblatt: Mobile Hochwasserschutzsysteme - Grundlagen für Planung und Einsatz, BWKBundesgeschäftsstelle, Sindelfingen, Deutschland, 2005.

Egli, T.: Entscheidungshilfe Mobiler Hochwasserschutz, Vereinigung Kantonaler Feuerversicherungen, Bern und Bundesamt für Wasser und Geologie, Biel, 2004.

FM Approvals: FM Approvals Homepage, available at: https:// www.fmapprovals.com/, last access: 25 September 2019.

Gabalda, V., Garvin, S., Hunter, K., Florence, C., Salagnac, J.-L., Golz, S., ten Veldhuis, M.-C., Diez, J., and Monnot, J. V.: Flood Resilience Technologies, SMARTeST, available at: https://www.ioer.de/fileadmin/internet/IOER_Projekte/PDF/ FB_R/Flood-Resilience-Technologies_SMARTeST-Project_ D23-final-July13.pdf (last access: 25 September 2019), 2013.

Massolle, C., Lankenau, L., and Koppe, B.: Emergency Flood Control: Practice-Oriented Test Series for the Use of Sandbag Replacement Systems, Geosciences, 8, 482, https://doi.org/10.3390/geosciences8120482, 2018.

McCormack, S. M., Van Dyke, C., Suazo A., and Kreis, D.: Temporary Flood Barriers, Research Report KYSPR-12-448, Kentucky Transportation Center, College of Engineering, University of Kentucky, Kentucky Transportation Cabinet Commonwealth of Kentucky and Federal Highway Administration U.S. Department of Transportation, Kentucky, 2012.

Mobildeich: Referenzen, available at: https://www.mobildeich.de/ de/referenz.php\#filme, last access: 25 September 2019.

National Flood Barrier Testing \& Certification Program (NFBTCP): Products, available at: https://nationalfloodbarrier.org/products/ \#!/prodsub-peri-barriers, last access: 25 September 2019.

Niedersaechsischer Landtag: Antwort auf eine Grosse Anfrage. Niedersaechsischer Landtag - 17. Wahlperiode, Drucksache 17/1730, available at: https://www.landtag-niedersachsen.de/ drucksachen/drucksachen_17_2500/1501-2000/17-1730.pdf (last access: 25 September 2019), 2014.

Ogunyoye, F., Stevens, R., and Underwood, S.: Delivering benefits through evidence. Temporary and Demountable Flood Protection Guide, Environment Agency, Bristol, 2011.

Österreichischer Wasser- und Abfallwirtschaftsverband (ÖWAV): Arbeitsbehelf 42: Mobiler Hochwasserschutz, Wien, 2013.

Pinkard, F., Pratt, T., Ward, D., Holmes, T., Kelley, J., Lee, L. T., Sills, G., Smith, E., Taylor, P. A., Torres, N., Wakeley, L., and Wibowo, J.: Flood-Fighting Structures Demonstration and Evaluation Program: Laboratory and Field Testing in Vicksburg, Mississippi, U.S. Army Corps of Engineers, Washington, 2007.

Popp, F., Lehmann, S., and Lehmann, B.: Flexibilität und Effizienz in der Deichverteidigung durch mobile Aufkadungssysteme, Wasserwirtschaft, 01, 29-33, 2019.

Simm, J., Sharp, M., Hemert, H. V., Igigabel, M., Pohl, R., Tourment, R., Wallis, M., Drake, C., Banks, J., Bramley, M., Chassé, P., Conforti, T., Jenkins, O., Mallet, T., Matheu, E., Royet, P., and Verigin, S. (Editorial Steering Board): The international levee handbook, C731, Construction Industry Research and Information Association (CIRIA), London, available at: https://www.ciria.org/ ItemDetail ?ProductCode $=\mathrm{C} 731 \mathrm{~F} \&$ Category $=$ FREEPUBS $\&$ 
WebsiteKey=3f18c87a-d62b-4eca-8ef4-9b09309c1c91 (last access: 25 September 2019), 2013.

Technisches Hilfswerk (THW): THW-pocket card "Hochwasserschutz und Deichverteidigung" ("flood protection and dyke defence"), status 02.08.2017, unpublished, THW Training Centre Hoya, Hoya, Germany, 2017.

Bundesministerium der Justiz und für Verbraucherschutz: Verordnung über die Durchführung und Abrechnung von Hilfeleistungen des Technischen Hilfswerks (THW-V), available at: http: //www.gesetze-im-internet.de/thw-abrv/anlage.html, last access: 16 March 2019.
VdS Schadenverhütung GmbH: Mobile Hochwasserschutzsysteme: Hinweise für die Beschaffung, den Einsatz und die Bereitstellung, VdS 6001: 2014 - 02 (01), Köln, 2014. 